\title{
Identification and control of subglacial water networks under Dome A, Antarctica
}

\author{
Michael J. Wolovick, ${ }^{1}$ Robin E. Bell, ${ }^{1}$ Timothy T. Creyts, ${ }^{1}$ and Nicholas Frearson ${ }^{1}$ \\ Received 11 July 2012; revised 8 October 2012; accepted 1 November 2012.
}

[1] Subglacial water in continental Antarctica forms by melting of basal ice due to geothermal or frictional heating. Subglacial networks transport the water from melting areas and can facilitate sliding by the ice sheet over its bed. Subglacial water flow is driven mainly by gradients in overburden pressure and bed elevation. We identify small (median $850 \mathrm{~m}$ ) water bodies within the Gamburtsev Subglacial Mountains in East Antarctica organized into long $(20-103 \mathrm{~km})$ coherent drainage networks using a dense $(5 \mathrm{~km})$ grid of airborne radar data. The individual water bodies are smaller on average than the water bodies contained in existing inventories of Antarctic subglacial water and most are smaller than the mean ice thickness of $2.5 \mathrm{~km}$, reflecting a focusing of basal water by rugged topography. The water system in the Gamburtsev Subglacial Mountains reoccupies a system of alpine overdeepenings created by valley glaciers in the early growth phase of the East Antarctic Ice Sheet. The networks follow valley floors either uphill or downhill depending on the gradient of the ice sheet surface. In cases where the networks follow valley floors uphill they terminate in or near plumes of freeze-on ice, indicating source to sink transport within the basal hydrologic system. Because the ice surface determines drainage direction within the bed-constrained network, the system is bed-routed but surface-directed. Along-flow variability in the structure of the freeze-on plumes suggests variability in the networks on long (10s of ka) timescales, possibly indicating changes in the basal thermal state.

Citation: Wolovick, M. J., R. E. Bell, T. T. Creyts, and N. Frearson (2013), Identification and control of subglacial water networks under Dome A, Antarctica, J. Geophys. Res. Earth Surf., 118, doi:10.1029/2012JF002555.

\section{Introduction}

[2] Subglacial water networks transport mass and energy underneath continental ice sheets. Their presence influences ice sheet thermal structure, rheology, and basal lubrication. Changes in basal lubrication are responsible for a wide range of dynamic ice sheet behavior, including streaming and surging [e.g., Cuffey and Paterson, 2010]. Networks with widths greater than several times the ice thickness have been traced using the characteristic signature they leave in ice surface curvature [Remy and Legresy, 2004]. Other water networks are active over timescales from months to years and have been traced by correlating the filling and draining cycles of active lakes identified using repeat-track analysis of satellite altimetry data [Gray et al., 2005; Fricker et al., 2007, 2010; Smith et al., 2009]. Satellite altimetry has also been used to identify active linkages between individual subglacial lakes [Wingham et al., 2006] identified previously using Radio-Echo Sounding

\footnotetext{
${ }^{1}$ Lamont-Doherty Earth Observatory, Columbia University, Palisades, New York, USA.

Corresponding author: M. J. Wolovick, Lamont-Doherty Earth Observatory, Columbia University, P.O. Box 1000, 61 Route 9W, Palisades, NY 10964-1000 USA. (mwolovic@1deo.columbia.edu)

(C)2012. American Geophysical Union. All Rights Reserved. 2169-9003/13/2012JF002555
}

(RES) data [Siegert et al., 2005]. Networks identified using satellite remote sensing tend to have lengths on the order of $10-100 \mathrm{~km}$, while the most abundant individual water bodies identified using RES are on the order of a few $\mathrm{km}$ wide [Dowdeswell and Siegert, 1999, 2003]. Other authors have located individual subglacial water bodies using RES measurements of reflectivity, morphology, hydraulic gradient, or basal roughness (e.g., Peters et al. [2005]; Carter et al. [2007]; Oswald and Gogineni [2008]). In this paper, we use a dense grid of RES data to identify hydrologic networks within the Gamburtsev Subglacial Mountains (hereafter, Gamburtsevs) in East Antarctica.

[3] The Gamburtsevs are a mountain range completely covered by ice and located underneath Dome A, the highest point of the East Antarctic Ice Sheet (EAIS) (Figures 1a and $1 \mathrm{~b}$ ). They were created by the rejuvenation of a Proterozoic orogenic crustal root during Permian and Cretaceous rifting [Ferraccioli et al., 2011]. The morphology of the mountains is dominated by a dendritic valley network created by a preglacial fluvial system overprinted by alpine-style glacial features during the early growth of the EAIS [Bo et al., 2009]. Erosion has been negligible since the EAIS was well established at 14-34 Ma [Cox et al., 2010; Jamieson et al., 2010]. The mountains have been shielded from subglacial erosion by low ice velocities [Rignot et al., 2011], the presence of cold-based ice [Pattyn, 2010], and by the widespread presence of basal freeze-on (accretion) that shielded 

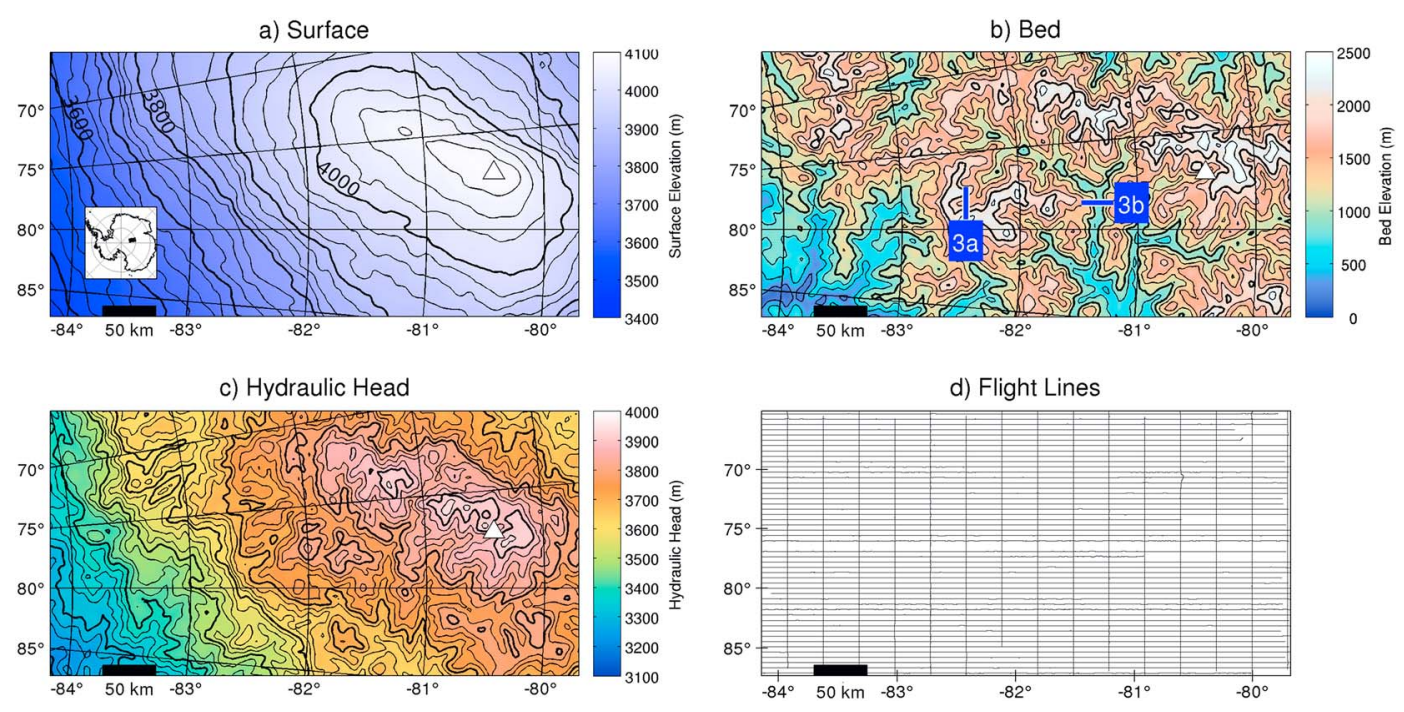

Figure 1. Geographic setting: (a) surface elevation relative to WGS84 from Bamber et al. [2009], smoothed at a $5 \mathrm{~km}$ wavelength, with thin contours at $25 \mathrm{~m}$ and thick contours at $100 \mathrm{~m}$, (b) bed elevation, gridded with a minimum curvature algorithm and smoothed at a $5 \mathrm{~km}$ wavelength, with thin contours at $250 \mathrm{~m}$ and thick contours at $1000 \mathrm{~m}$. Blue lines show the locations of the radar echograms in Figure 3, (c) hydraulic head, calculated from (a) and (b), with thin contours at $25 \mathrm{~m}$ and thick contours at $100 \mathrm{~m}$, and (d) distribution of the flight lines that were used for this study. Inset map shows survey area in relation to the Antarctic grounding line.

the mountain peaks from contact with subglacial water [Creyts et al., in review]. Accretion processes appear to be active, producing what have been described as "valley head" and "valley wall" accretion ice reflectors [Bell et al., 2011a]. The valley head reflectors form organized plumes of accreted ice that are imaged up to $100 \mathrm{~km}$ from their source regions in the direction of ice flow. Five of the nine networks we identify terminate at or near the source regions of valley head accretion reflectors identified by Bell et al. [2011a], indicating source to sink transport within the basal hydrologic system.

\section{Methods}

\subsection{Survey}

[4] The data presented in this paper were collected in December 2008 and January 2009 by the AGAP (Antarctic's Gamburtsev Province Project) expedition as part of the International Polar Year 2007-2009. The main grid lines of this survey are spaced $5 \mathrm{~km}$ apart and oriented roughly parallel to local north, while the tie lines are spaced $33 \mathrm{~km}$ apart and oriented roughly parallel to local east (Figure 1d). The survey was conducted with two Twin Otter aircraft equipped with ice-penetrating radars, laser ranging systems, gravimeters, and magnetometers. The two planes were based at separate camps (AGAP-S and AGAP-N) that surveyed the southern and northern halves of the grid, respectively. The area surveyed from AGAP-S was located over the summit and southern flank of Dome A, while the area surveyed from AGAP-N included the transition from the northern flank of Dome A into the fast flowing Lambert Glacier. To avoid complications associated with interpreting data from different radar systems and glaciological regimes we simply report on data collected from AGAP-S in this paper.

\subsection{Radar System and Processing}

[5] The Lamont-Doherty Earth Observatory radar system, based on designs from the Center for the Remote Sensing of Ice Sheets [Gogineni et al., 2001; Jezek et al., 2006], has a center frequency of $150 \mathrm{MHz}$, a bandwidth of $10 \mathrm{MHz}$, and a transmit power of $800 \mathrm{~W}$. The system transmits a low-gain $3 \mu$ s and a high-gain $10 \mu$ s pulse that are combined in postprocessing. Before decimation, the average along-track trace spacing is $1.3 \mathrm{~m}$ and the range bin sample size is $0.7 \mathrm{~m}$ in ice. The data are pulse compressed and then migrated with a 1D Synthetic Aperture Radar algorithm assuming point scattering targets following Heliere et al. [2007]. The time resolution of the pulse compression algorithm is $10^{-7} \mathrm{~s}$, or $8.4 \mathrm{~m}$ of range in ice. We scale the matched filter of the migration algorithm to eliminate the effect of aperture size on echo power by dividing the filter by the number of bins over which it is applied. The along-track resolution of the SAR algorithm (reciprocal of the Doppler bandwidth) is depth-dependent, but is $20 \mathrm{~m}$ for ice depths typical of the Gamburtsevs. The data are decimated by a factor of 10 , resulting in a final resolution of $13 \mathrm{~m}$ in the horizontal and $7 \mathrm{~m}$ in the vertical. The bed echo is picked with a hybrid manual-automatic system using the steepest vertical gradient or the rising edge of the signal to represent the bed depth. The bed returned power is the brightest pixel within $50 \mathrm{~m}$ of the bed depth. We low-pass filter the output of the picking algorithm along track at $60 \mathrm{~m}$. The ice thickness measurements have an RMS crossover error of $69 \mathrm{~m}$, and the bed returned power measurements, corrected for geometric spreading, have an RMS crossover error of $6.0 \mathrm{~dB}$. Of the $6.0 \mathrm{~dB}$ errors in bed returned power, $3.7 \mathrm{~dB}$ can be attributed to variability in transmitted power and system characteristics, as measured by the standard deviation of the direct arrival. Ice thickness is gridded using a minimum curvature 
algorithm and then smoothed using a Gaussian filter with a standard deviation of $2.5 \mathrm{~km}$, corresponding to a nominal cutoff wavelength equal to the line spacing of $5 \mathrm{~km}$. Ice thickness is converted to bed elevation using the surface Digital Elevation Model (DEM) from Bamber et al. [2009], smoothed in the same manner as the ice thickness grid.

\subsection{Water Identification}

[6] We use the intersection of two methods to identify subglacial water bodies: reflectivity analysis and manual digitization. In the reflectivity analysis we correct observed bed echo power for englacial attenuation to map reflectivity anomalies. We use high reflectivity anomalies to differentiate potential water bodies. In the manual digitization analysis an operator examines the radar echograms and selects reflectors as potential water bodies on the basis of their morphological fit to specified criteria (section 2.5). The output of the first method is a set of individual points exceeding the reflectivity threshold, and the output of the second method is a set of line segments corresponding to discrete reflectors that meet the criteria. We combine the outputs from both methods by picking those candidates that contain bright reflectivity anomalies within their horizontal extent to produce our highest confidence identification of water bodies.

\subsection{Reflectivity Anomalies}

[7] To convert the observed echo power to basal reflectivity anomalies we correct for geometric spreading, assuming spreading scales with the inverse squared power of the range. The observed echo power has a range of $119 \mathrm{~dB}$. While the absolute magnitude of the geometric correction is large $($ mean $=64.7 \mathrm{~dB})$, the variability is small (range $=$ $9.2 \mathrm{~dB}$, standard deviation $=1.38 \mathrm{~dB}$ ). Most of the observed variability in echo power comes from sources other than geometric spreading. The radar equation we use, following the notation of Matsuoka et al. [2010], is

$$
[\mathrm{P}]_{\mathrm{dB}}=[\mathrm{K}]_{\mathrm{dB}}-2[\mathrm{~L}]_{\mathrm{dB}}-[\mathrm{G}]_{\mathrm{dB}}+[\mathrm{R}]_{\mathrm{dB}}
$$

where square brackets represent quantities in the decibel scale $\left([\mathrm{X}]_{\mathrm{dB}}=10 * \log _{10}(\mathrm{X})\right), \mathrm{P}$ is the observed echo power, $\mathrm{K}$ is a constant term including transmitted power, system gain, processing gain, birefringence, and surface transmission, L represents one-way attenuation losses, $G$ represents geometric spreading losses, and $\mathrm{R}$ represents basal reflectivity, the desired signal. We assume losses from birefringence and surface transmission to be constant. Correcting the received signal for geometric spreading losses produces geometrically corrected power $\mathrm{P}^{\mathrm{c}}$, which is

$$
\left[\mathrm{P}^{\mathrm{c}}\right]_{\mathrm{dB}}=[\mathrm{P}]_{\mathrm{dB}}+[\mathrm{G}]_{\mathrm{dB}}
$$

where geometric spreading losses are $[\mathrm{G}]_{\mathrm{dB}}=2[\mathrm{H}+\mathrm{D} / \mathrm{n}]_{\mathrm{dB}}$, $\mathrm{H}$ is the height of the aircraft above the ice surface, $\mathrm{D}$ is the ice depth, and $n=\varepsilon^{1 / 2}=1.78$ is the index of refraction of ice.

[8] Anomalies in $\left[\mathrm{P}^{\mathrm{c}}\right]_{\mathrm{dB}}$ are caused by either changes in basal reflectivity $[\mathrm{R}]_{\mathrm{dB}}$ or changes in attenuation $[\mathrm{L}]_{\mathrm{dB}}$. To remove the effects of attenuation, we perform a regional attenuation correction based on a linear best fit to a plot of $\left[\mathrm{P}^{\mathrm{c}}\right]_{\mathrm{dB}}$ vs. D [Jacobel et al., 2010]. The regional attenuation correction is applied over the survey area seen in Figure 1 $(250 \mathrm{~km} \times 500 \mathrm{~km})$. For comparison, the Jacobel et al. [2010] correction applied to a single traverse line $1700 \mathrm{~km}$ long. The AGAP regional attenuation correction has a oneway slope of $11.7 \mathrm{~dB} / \mathrm{km}$ and a correlation coefficient of -0.83 (Figure 2). This correction represents the mean dependence of total attenuation from all sources on ice thickness between separate sites, not the depth-averaged attenuation rate at any one site. Total attenuation is the integral of local attenuation rate over the ice thickness. Local attenuation rate depends weakly on the concentration of chemical impurities and strongly on ice column temperature [MacGregor et al., 2007] with temperature in turn depending on ice thickness and thermal boundary conditions (geothermal flux, accumulation rate, and surface temperature). The regional attenuation correction simply represents an empirical measure of the first-order dependence of geometrically corrected returned power on ice thickness (Figure 2) without considering the nonlinear dependence of attenuation rate on ice thickness. We address the robustness of our interpreted water networks to changes in attenuation rate in more detail in the discussion (section 4.1). The residual to the best fit correction is the reflectivity anomaly $\Delta[\mathrm{R}]_{\mathrm{dB}}$.

[9] We correct for horizontal deviations from the regional average attenuation rate by removing a long-wavelength signal from $\Delta[\mathrm{R}]_{\mathrm{dB}}$. Horizontal deviations in attenuation rate are expected based on variations in temperature caused by changing boundary conditions and ice thickness [Matsuoka, 2011]. However, horizontal advection from ice flow acts to smooth out small scale changes in boundary conditions. On the one hand, consider the characteristic diffusive equilibration time $t$ of an ice sheet with the average ice thickness in our survey area $\mathrm{D}=2.5 \mathrm{~km}: \mathrm{t}=\mathrm{D}^{2} / \kappa \sim 150 \mathrm{ka}$, with diffusivity $\kappa=1.3 \times 10^{-6} \mathrm{~m}^{2} \mathrm{~s}^{-1}$. Equating horizontal advective timescales with vertical diffusive timescales, and assuming ice moves at a rate of $1 \mathrm{ma}^{-1}\left(1.7 \mathrm{ma}^{-1}\right.$ measured at AGAP-S, Bell et al. [2011a]), this corresponds to a flow line averaging length of $150 \mathrm{~km}$. On the other hand, horizontal velocity should be slower near the bed and near the dome, suggesting a smaller averaging length may be appropriate. We use an averaging window of $50 \mathrm{~km}$ with a Gaussian filter (standard deviation $=25 \mathrm{~km}$ ), while acknowledging that the full solution to this problem would involve a 3D thermomechanical model of the ice sheet around Dome A. The reflectivity anomaly with the long-wavelength signal (section 3.1) removed is called the short-wavelength reflectivity anomaly $\Delta\left[\mathrm{R}^{\mathrm{sw}}\right]_{\mathrm{dB}}$. To preserve our ability to detect small water bodies we do not attempt to use a griding algorithm on $\Delta\left[\mathrm{R}^{\mathrm{sw}}\right]_{\mathrm{dB}}$. Instead, we identify points with values of $\Delta\left[\mathrm{R}^{\mathrm{sw}}\right]_{\mathrm{dB}}$ exceeding one of two thresholds, discussed below.

[10] We aim to create a conservative list of reflectors we are confident are water bodies, rather than to make an exhaustive list of all possible water in the Gamburtsevs. Our goal in threshold selection is to minimize false positives at the expense of allowing false negatives. We use thresholds based on the statistics of the $\Delta\left[\mathrm{R}^{\mathrm{sw}}\right]_{\mathrm{dB}}$ dataset, 3 and 4 standard deviations $(+19.4 \mathrm{~dB}$ and $+25.9 \mathrm{~dB}$, corresponding to probabilities of $\mathrm{p}<0.13 \%$ and $\mathrm{p}<0.0032 \%$ for an ideal normal distribution) to distinguish potential water bodies. We discuss below how the number of points identified as potential water bodies changes with each threshold (sections 3.1, 3.3). Other authors have used a range of thresholds to delineate basal water. The expected reflectivity contrast between wet and dry beds is $10-15 \mathrm{~dB}$ [Peters et al., 2005], although this value is sensitive to basal roughness and 


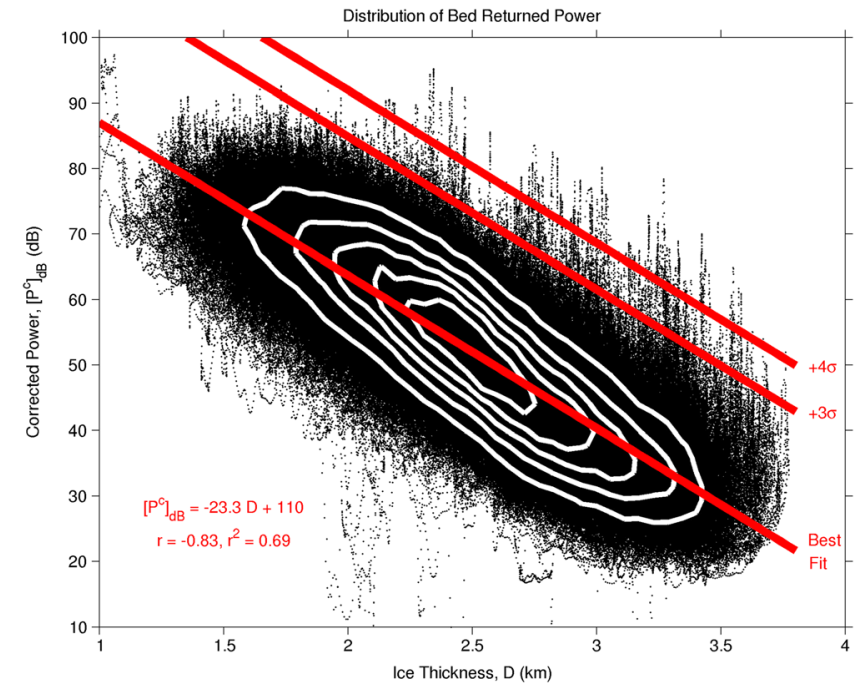

Figure 2. Distribution of geometrically corrected bed returned power with respect to ice thickness. White contours represent the probability density function of the data. Red lines represent the best fit regional attenuation cutoffs and $3 \sigma, 4 \sigma$ thresholds for comparison. In practice the thresholds are defined and applied after the long-wavelength signal from Figure $4 \mathrm{a}$ is removed.

the salinity of the water. MacGregor et al. [2012] and Matsuoka [2011] described $10 \mathrm{~dB}$ as the "nominal" threshold for distinguishing wet and dry beds. Dowdeswell and Siegert [2003] used the range of 10-20 dB. Jacobel et al. [2010] identified two overlapping, normally distributed populations (wet and dry) with a mean difference of $7 \mathrm{~dB}$. Oswald and Gogineni [2008] found two overlapping normal distributions with means separated by $10 \mathrm{~dB}$. Peters et al. [2005] used a gradation of bed reflectivity spanning $24 \mathrm{~dB}$ to distinguish basal conditions with varying degrees of water coverage and saturation. Carter et al. [2007] used a threshold of $2 \mathrm{~dB}$, relative to a water body's immediate surroundings, as one of several criteria to define "definite lakes". Our $19.4 \mathrm{~dB}$ and $25.9 \mathrm{~dB}$ thresholds are more conservative than previous studies to minimize the identification of dry bed as wet (false positives) at the expense of allowing some wet bed to go undetected (false negatives).

\subsection{Manual Digitization}

[11] Visual inspection of radar echograms has been used extensively to identify subglacial water bodies [Oswald and Robin, 1973; Siegert et al., 1996, 2005]. To minimize subjectivity, we established the picking criteria before digitization began. Our criteria are (1) brightness relative to surroundings at a similar depth, (2) location at or near a topographic minimum, (3) echo abruptness (vertical thinness), and (4) hydraulic flatness. Visible drawdown of the ice sheet stratigraphy indicates highly localized melt rates and can be supporting evidence for identifying basal water. Because basal water can flow away from melt sources, and melt rates must be large relative to horizontal ice velocity for drawdown to be visible, we have not used drawdown as a primary criterion for identifying water. We use the criterion of echo abruptness as a proxy for specularity, or basal smoothness [Oswald and Robin, 1973]. A rough bed will reflect energy back toward the aircraft from a wider range of angles than a smooth bed that appears at a greater range in an echogram than the nadir echo. We classify reflectors that unambiguously meet all of the criteria as "clear picks", and reflectors for which some of the criteria are absent or ambiguous "unclear picks" (Figure 3). Both types of picks are considered water "candidates".

[12] During digitization, candidates are picked by an operator examining the radar data on a computer monitor and selecting endpoints of linear reflectors that meet the criteria. The operator has to make a subjective decision whether a given reflector represents a contiguous morphological feature. The distance between the endpoints represents the length of the candidate. To prevent the possibility of introducing a bias into the data, the same operator picked the entire dataset. The operator has to be able to see enough detail in the echogram to judge that the criteria have been met before selecting a candidate. In practice it is difficult for an operator to assess whether the criteria have been met for candidates less than two to three hundred meters long ( 20 pixels). To ensure we only pick candidates that are

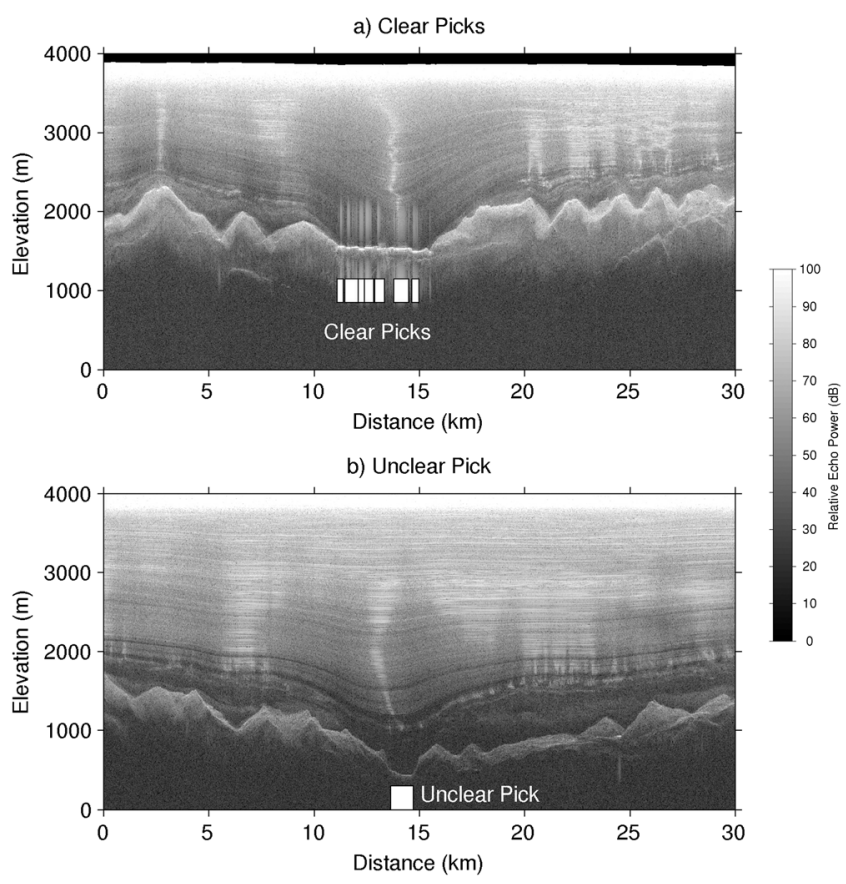

Figure 3. Examples of clear and unclear picks encountered in the manual digitization process (both radar echograms have been elevation-adjusted and returns above the surface have been blanked out; the color scale has a range of $100 \mathrm{~dB}$ ): (a) examples of clear manual picks and (b) an example of an unclear manual pick. The clear picks in (a) are not only brighter than the other valleys in the image, they are brighter than the peaks as well, even though valleys should experience more attenuation than peaks. There are small apparent vertical offsets between the clear picks in (a) but individual water bodies are both flat and vertically thin. In addition, drawdown of the ice sheet stratigraphy indicates basal melt here. The unclear pick in (b) is flat in its right half and vertically thin throughout, but there are no nearby reflectors at comparable depth to compare against. The bright reflector near $25 \mathrm{~km}$ in (b) is a clear pick with a length of $0.37 \mathrm{~km}$, near the limit of the resolution of manual digitization. 


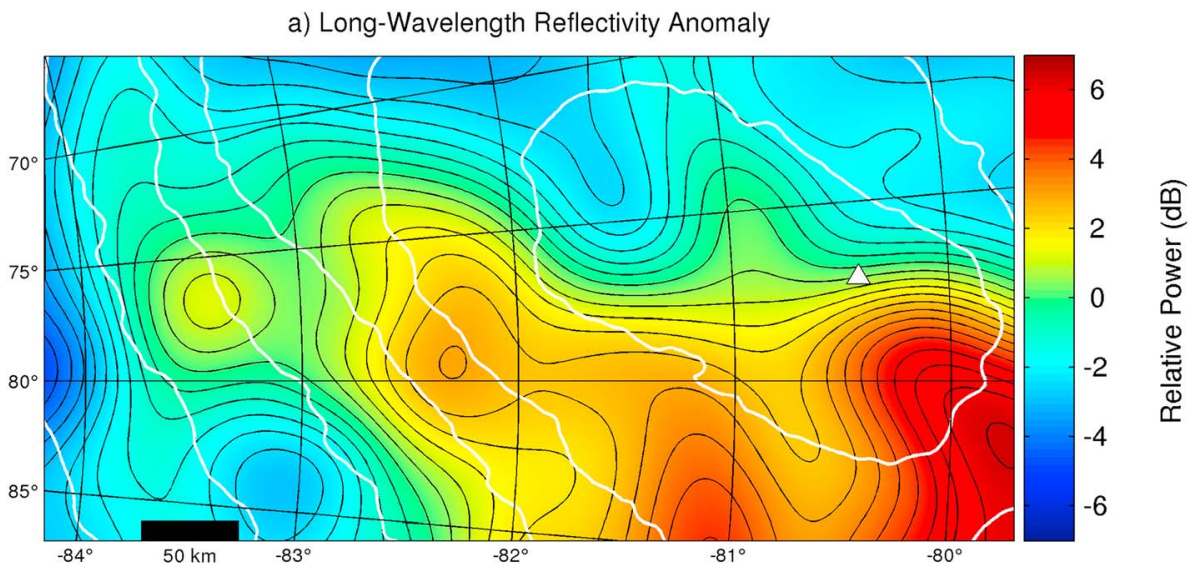

b) Short-Wavelength Reflectivity Anomalies

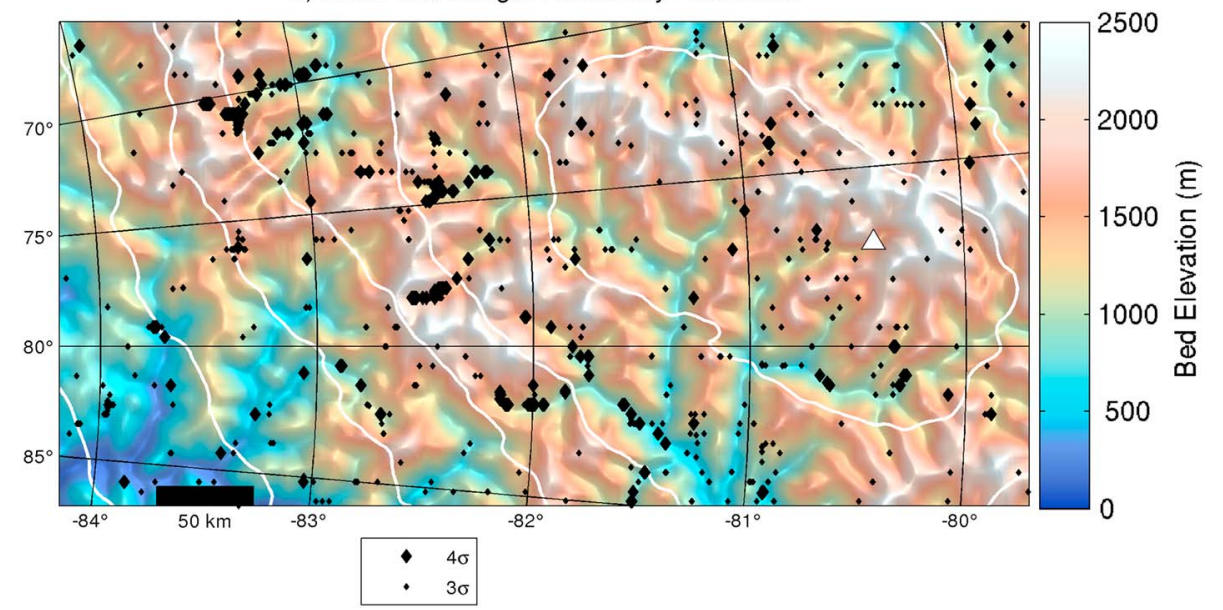

Figure 4. Reflectivity anomalies: (a) long-wavelength $(50 \mathrm{~km})$ reflectivity anomaly and (b) shortwavelength reflectivity anomalies that passed the $3 \sigma$ and $4 \sigma$ thresholds overlain on bed elevation. Hill shading for bed elevation is from two perpendicular light sources, one at the top of the page and one to the right of the page, both at an elevation of $75^{\circ}$ above the horizon. Large diamonds represent $4 \sigma$ points and small diamonds represent $3 \sigma$ points. White lines are $100 \mathrm{~m}$ surface elevation contours.

hydraulically flat, we discard candidates with a range in hydraulic head greater than the uncertainty in hydraulic head, described below.

\subsection{Hydraulic Head}

[13] Subglacial water flows down the gradient of hydraulic head, a quantity calculated from both the ice surface and the bed elevation, although surface gradients are weighted roughly 11 times more than bed gradients in driving water flow [Shreve, 1972; Clarke, 2005]. Assuming water pressure is equal to ice overburden pressure, hydraulic head (h), is calculated from surface elevation (S), bed elevation (B), and ice thickness $(D=S-B)$, via

$$
\begin{gathered}
\mathrm{h}=\left(\rho_{\mathrm{i}} / \rho_{\mathrm{w}}\right) \mathrm{D}+\mathrm{B} \\
\mathrm{h}=\left(\rho_{\mathrm{i}} / \rho_{\mathrm{w}}\right) \mathrm{S}+\left(1-\rho_{\mathrm{i}} / \rho_{\mathrm{w}}\right) \mathrm{B},
\end{gathered}
$$

with ice density $\rho_{\mathrm{i}}=917 \mathrm{kgm}^{-3}$, and water density $\rho_{\mathrm{w}}=$ $1000 \mathrm{kgm}^{-3}$ [Shreve, 1972; Clarke, 2005]. Hydraulic head is calculated along flight lines and for the gridded DEM. To determine the uncertainty in hydraulic head along flight lines we propagate the crossover errors in bed elevation and the error in the surface DEM (mean value of $2.6 \mathrm{~m}$ within our survey area [Bamber et al., 2009]) through equation 3b, assuming that the crossover error in ice thickness represents the error in bed elevation. The root-mean-square uncertainty in hydraulic head is $8.2 \mathrm{~m}$. To determine drainage routes and catchment area, we apply a routing algorithm to the gridded hydraulic head after first filling closed basins. We use a multiple slope routing algorithm [Quinn et al., 1991]. Hillslope routing algorithms have been used extensively to delineate subglacial flow paths beneath both glaciers and ice sheets (e.g., Flowers and Clarke [1999]; Le Brocq et al. [2009]; Pattyn [2010]). Basins are filled by iteratively raising each grid cell a small spillover amount above its sill level. Less than $5 \%$ of the grid cells require basin fill, with a mean fill level of $4 \mathrm{~m}$. The maximum basin fill required for any single grid cell is $24 \mathrm{~m}$.

\section{Results}

\subsection{Reflectivity Anomalies}

[14] The long-wavelength reflectivity anomalies are characterized by an east-west gradient in the north of the survey grid, with the highest values occurring in the northeast corner (Figure $4 a$ ). In the south of the survey grid, the long-wavelength 

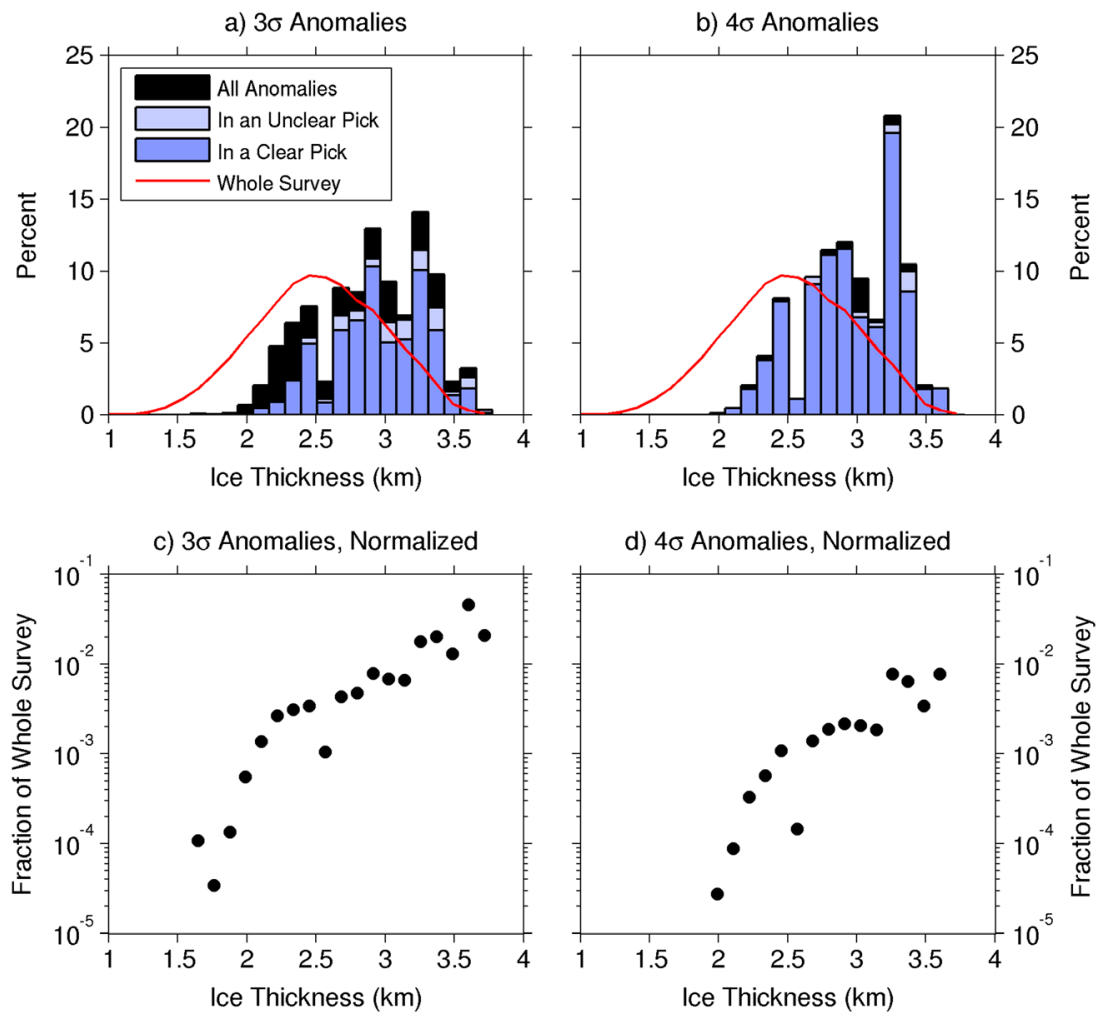

Figure 5. Distribution of ice thickness for the reflectivity anomalies: (a) distribution of ice thickness for $3 \sigma$ reflectivity anomalies. Black bars represent all anomalies, light blue bars represent anomalies contained within unclear picks, dark blue bars represent anomalies contained within clear picks, and the red line represents the distribution of ice thickness for the entire dataset, (b) same as (a), but for $4 \sigma$ anomalies, (c) distribution of ice thickness for $3 \sigma$ anomalies, normalized by the distribution of ice thickness for the overall dataset and plotted on semilogarithmic axes, and (d) same as (c), but for $4 \sigma$ anomalies.

reflectivity anomalies are characterized by a central high flanked by lows on the east and west edges. If the longwavelength reflectivity anomalies represent thermal structure, the lows correspond to warm regions and the highs to cold regions. Long-wavelength patterns in the thermal boundary conditions - geothermal flux, accumulation rate, and surface temperature - can produce a signal in thermal structure, as can long-wavelength patterns in ice thickness or strain heating. However, long-wavelength patterns in the impurity content of the ice or water distribution at the bed can also produce a signal in long-wavelength reflectivity [MacGregor et al., 2012]. Further interpretation of the longwavelength reflectivity signal will require studies of the ice sheet thermal structure, local climate history, and subglacial geology.

[15] The short-wavelength reflectivity anomalies contain 9073 points $(0.44 \%$ of the total $)$ at the $3 \sigma$ level and 2682 points $(0.13 \%)$ at the $4 \sigma$ level. These percentages are 3 times and 40 times as large, respectively, as would be expected for an ideal normal distribution. Previous studies [Oswald and Gogineni, 2008; Jacobel et al., 2010] show that basal reflectivity is well fit by two overlapping normal distributions (wet bed and dry bed). These results give us confidence that we are sampling a small wet bed distribution rather than the tail of the dry bed distribution. Both sets of points are generally located in local topographic minima, and several valleys contain distinct clusters of $4 \sigma$ anomalies (Figure $4 \mathrm{~b}$ ). The minimum ice thicknesses containing $3 \sigma$ and $4 \sigma$ anomalies are $1645 \mathrm{~m}$ and $1971 \mathrm{~m}$, respectively. The raw distributions of ice thickness for both sets of points show broad maxima between 2500 and $3500 \mathrm{~m}$ (Figures 5a and $5 \mathrm{~b}$ ). When the distributions are normalized by the overall ice thickness dataset they show a strong increase in the fraction of the basal area containing reflectivity anomalies with increasing ice thickness (Figures 5c and 5d). However, even at large ice thicknesses the reflectivity anomalies are a small percentage of the total basal area. No single ice thickness contains more than $5 \%$ of $3 \sigma$ reflectivity anomalies or $1 \%$ of $4 \sigma$ reflectivity anomalies. Overall, these results are consistent with subglacial water that is generated by melting in deep valleys.

\subsection{Manual Digitization}

[16] Digitized candidates are found throughout the valley networks of the Gamburtsevs, but often cluster in the valleys that also have groups of reflectivity anomalies (Figure 6a, cf. Figure 4b). There are 172 clear picks and 300 unclear picks, of which 161 and 254 (94\% and 85\%) passed the hydraulic flatness criterion. These include $0.59 \%$ and $0.69 \%$ of all data points, respectively. Clear picks are rare in the southeast corner (lower left on all map figures) of the grid, where the thickest ice is located, although scattered candidates are present in valleys throughout the survey area (Figure 6a). The absence of water in the southeastern portion of the study area may be because downhill flow limits ponding and prevents us from detecting basal water, as 


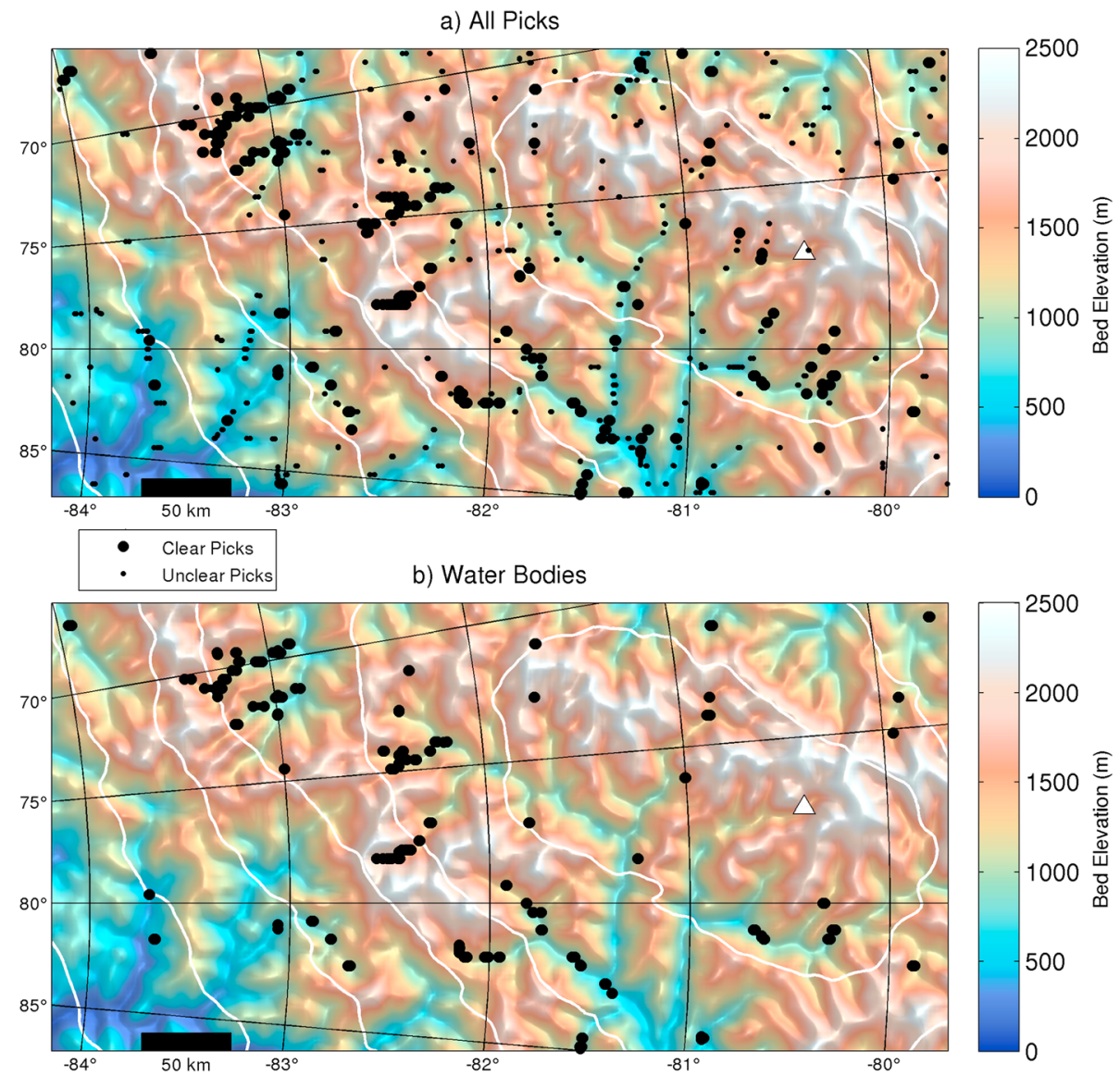

Figure 6. Manually digitized candidates: (a) all manually picked candidates overlain on bed elevation. Hill shading is identical to Figure 4b. Large black circles represent clear picks and small black circles represent unclear picks. White lines represent $100 \mathrm{~m}$ surface elevation contours and (b) the subset of clear picks that also contain $4 \sigma$ reflectivity anomalies. This intersection set represents the candidates we are most confident actually represent water bodies.

discussed later (section 3.4). It could also be because thermal boundary conditions are different and meltwater is not generated here. As with the reflectivity anomalies, the raw distributions of ice thickness within the candidates display broad maxima between 2500 and $3500 \mathrm{~m}$ (Figures $7 \mathrm{a}$ and $7 \mathrm{~b}$ ), while the normalized distributions show a strong increase in the fraction of the bed contained by candidates with increasing ice thickness (Figures $7 \mathrm{c}$ and $7 \mathrm{~d}$ ). Manual digitization identifies a larger fraction of the deep ice containing water than the reflectivity analysis, at $23 \%$ for the unclear picks and 14\% for the clear picks (Figures $7 \mathrm{c}$ and $7 \mathrm{~d}$, cf. Figures 5c and 5d).

\subsection{Overlap of Methods}

[17] The candidates most likely to represent water bodies are those that are both clear picks and contain $4 \sigma$ reflectivity anomalies, the intersection set (Table 1). A majority, 65\%, of the clear picks fall into this category. In contrast, only $4 \%$ of the unclear picks contain $4 \sigma$ reflectivity anomalies. The set of $4 \sigma$ anomalies is nearly as exclusive as the intersection set, with $91 \%$ of its members contained within a clear pick versus $62 \%$ for the set of $3 \sigma$ anomalies.

[18] The lengths of water bodies we find in the intersection set are shorter than most of the subglacial lakes that have been found by previous studies (Figure 8). We compare the water bodies we find with those described by Carter et al. [2007] (accessed via Blankenship et al., [2009]) and Siegert et al. [2005], using kernel density estimation to approximate the underlying continuous distribution from our discrete sample [Bowman and Azzalini, 1997]. The median value of our distribution is $850 \mathrm{~m}$, substantially smaller than most previously discovered subglacial lakes. The Carter et al. [2007] inventory has a bimodal distribution with peaks at $4 \mathrm{~km}$ and $10 \mathrm{~km}$, and the Siegert et al. [2005] inventory has a single broad peak with a maximum near $6 \mathrm{~km}$. Our distribution may be skewed toward smaller water bodies because of the closer line spacing in the AGAP survey. Where the flight line spacing in the AGAP survey is $5 \mathrm{~km}$, the Carter et al. [2007] inventory was drawn from three surveys with line spacings between $5-10 \mathrm{~km}$, and the Siegert et al. [2005] inventory was drawn from many surveys with line spacings in the range of 5-50 km. However, while dense line spacing can explain why we do observe more small water bodies than previous surveys, it cannot explain why we do not observe any large water bodies. A more likely explanation is that rugged topography within the Gamburtsevs concentrates water within small bedrock depressions. The Gamburtsevs are considered to be among the roughest 

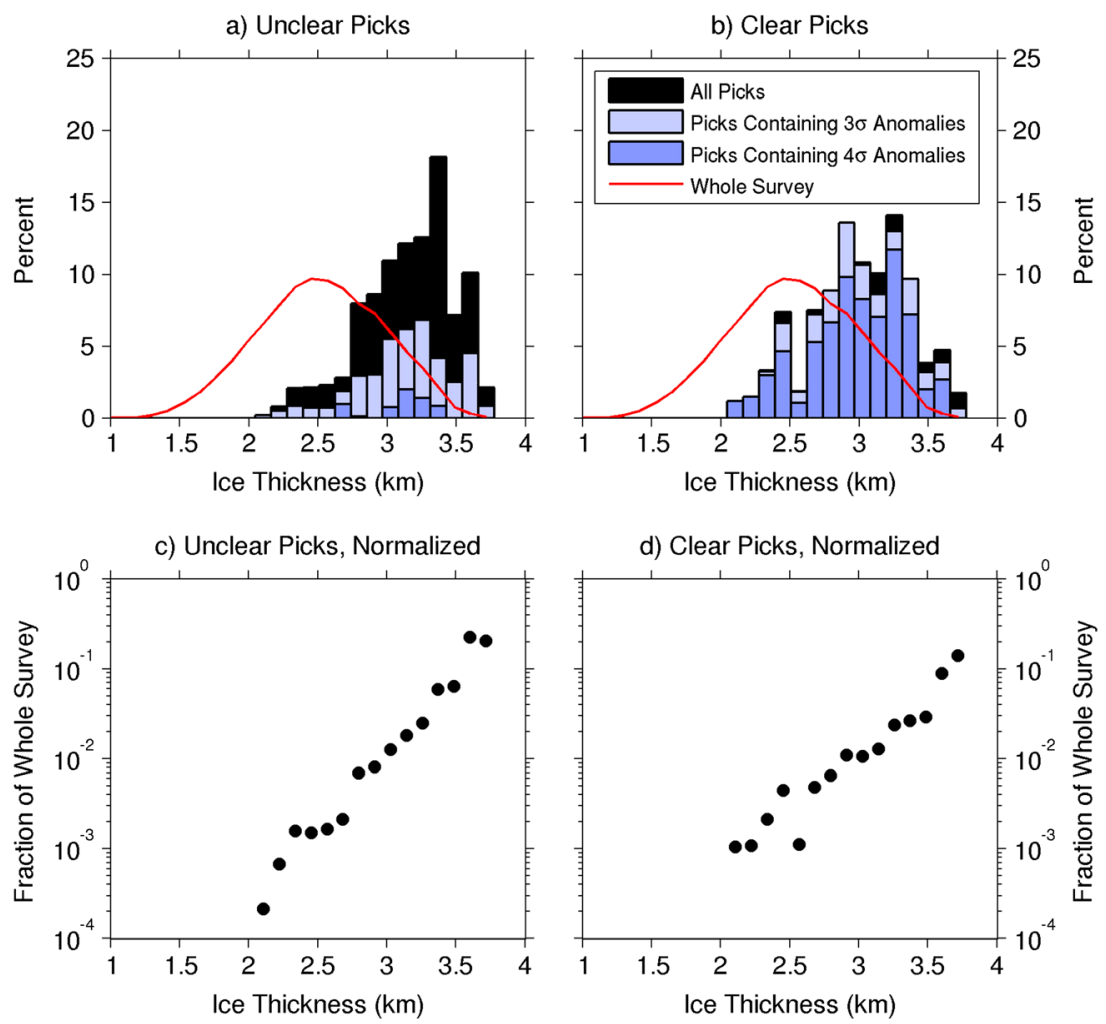

Figure 7. Distribution of ice thickness for points within manually digitized water bodies: (a) distribution of ice thickness for unclear picks. Black bars represent the ice thickness of all unclear picks, light blue bars represent unclear picks containing $3 \sigma$ reflectivity anomalies, dark blue bars represent unclear picks containing $4 \sigma$ anomalies, and the red line represents the distribution of ice thickness for the entire dataset, (b) same as (a), but for clear picks, (c) distribution of ice thickness for points within unclear picks, normalized by the distribution of ice thickness for the overall dataset and plotted on semilogarithmic axes, and (d) same as (c), but for clear picks.

subglacial topography in Antarctica [Ferraccioli et al., 2011]. Elsewhere in Antarctica, broad subglacial basins trap large subglacial lakes, but the Gamburtsevs are dominated by prominent peaks dissected by deep valleys that only allow water to collect in small bedrock depressions.

\subsection{Water Networks}

[19] Most of the water bodies in the intersection set are clustered into 9 distinct networks that we label alphabetically A-I (Figure 9). Seven of the nine networks (all except $\mathrm{G}$ and I) flow uphill toward shallower ice with conditions that favor conductive cooling of the bed. All 9 networks fall along parts of drainage pathways determined by the hydraulic routing algorithm, and all are located within bedrock valleys (Figure 9). The networks we observe have lengths ranging from 20 to $103 \mathrm{~km}$ and catchment areas ranging from 1700 to $8700 \mathrm{~km}^{2}$ (Table 2). Average hydraulic gradients in the networks are on the order of $10^{-4}-10^{-3}$, while average ice thickness gradients are on the order of $10^{-3}-10^{-2}$. Four of the networks that flow uphill terminate in the source regions for the valley head accretion ice imaged by Bell et al. [2011a] (Figure 9). The networks may be terminated by loss of water through freeze-on to the overlaying ice sheet, or some of the water may pass through the freeze-on region and continue undetected (e.g., as narrow channels, thin films, or groundwater flow). One of the networks that does not terminate in a plume of valley head accretion ice, network B, terminates $20 \mathrm{~km}$ short of a valley head accretion plume. The separation between the end of the network and the start of the accretion plume suggests either episodic fluctuations in the network extent and accretion process or that the water is undetected. One of the other networks that does not terminate in a plume of valley head accretion ice, network $H$, terminates near a plume of valley wall accretion ice. Network F flows out of the eastern edge of the survey grid. The remaining two networks, $\mathrm{G}$ and I, terminate within our survey grid without producing accretion plumes and are also the only two networks to flow downhill. Our method is optimized for identifying ponded water rather than other morphologies, and downhill flow may be associated with higher hydraulic gradients (Table 2) that inhibit ponding of basal water and prevent us from detecting the full extent of these networks. As a result, the water networks we observe may be biased toward uphill flow. The difficulty in imaging downhill flowing networks may explain why we observe little water in the southeast corner of the survey grid (Figures 4, 6, and 9), despite thick ice there. It is also possible that thermal boundary conditions are different and the bed is cold here. Overall, the networks are confined within bedrock valleys, and a majority flow uphill and terminate near the source regions of basal freeze-on ice.

[20] All of the water networks are composed of discrete individual water bodies with irregular shapes. In some cases 
Table 1. List of Water Bodies in the Intersection Set, Clear Picks Which Also Contain $4 \sigma$ Reflectivity Anomalies

\begin{tabular}{|c|c|c|c|c|c|}
\hline Number & Lat & Lon & $\begin{array}{l}\text { Length } \\
(\mathrm{km})\end{array}$ & $\begin{array}{l}\text { Ice Thickness } \\
(\mathrm{m})\end{array}$ & Network \\
\hline 1 & -79.705 & 71.957 & 0.74 & 3014 & - \\
\hline 2 & -83.940 & 66.754 & 1.78 & 3088 & - \\
\hline 3 & -80.789 & 71.284 & 1.17 & 3349 & - \\
\hline 4 & -82.889 & 69.453 & 1.25 & 3328 & A \\
\hline 5 & -81.673 & 70.990 & 0.64 & 2487 & - \\
\hline 6 & -83.155 & 69.424 & 0.61 & 2919 & A \\
\hline 7 & -82.949 & 69.735 & 3.05 & 3248 & $\mathrm{~A}$ \\
\hline 8 & -82.973 & 69.700 & 0.63 & 3208 & A \\
\hline 9 & -83.149 & 69.818 & 0.81 & 2960 & A \\
\hline 10 & -83.041 & 69.976 & 1.55 & 3141 & A \\
\hline 11 & -83.062 & 69.944 & 1.13 & 3096 & A \\
\hline 12 & -83.180 & 70.154 & 2.57 & 2927 & A \\
\hline 13 & -82.318 & 71.251 & 0.33 & 2720 & - \\
\hline 14 & -83.415 & 70.198 & 3.67 & 2461 & $\mathrm{~A}$ \\
\hline 15 & -83.235 & 70.458 & 2.13 & 2871 & A \\
\hline 16 & -83.310 & 70.746 & 7.50 & 2699 & A \\
\hline 17 & -83.259 & 70.818 & 0.71 & 2740 & A \\
\hline 18 & -82.882 & 71.296 & 2.71 & 3287 & B \\
\hline 19 & -82.991 & 71.536 & 1.21 & 3192 & B \\
\hline 20 & -82.971 & 71.554 & 1.55 & 3225 & B \\
\hline 21 & -81.715 & 72.828 & 0.23 & 2934 & - \\
\hline 22 & -80.845 & 73.505 & 0.35 & 3143 & $\mathrm{H}$ \\
\hline 23 & -79.904 & 74.108 & 0.35 & 3207 & - \\
\hline 24 & -83.087 & 71.792 & 6.36 & 3065 & B \\
\hline 25 & -83.000 & 72.263 & 0.28 & 3156 & B \\
\hline 26 & -80.861 & 74.063 & 1.94 & 3272 & $\mathrm{H}$ \\
\hline 27 & -83.210 & 72.410 & 1.59 & 2881 & B \\
\hline 28 & -79.948 & 75.114 & 0.39 & 2995 & - \\
\hline 29 & -82.228 & 74.025 & 1.30 & 3297 & $\mathrm{C}$ \\
\hline 30 & -82.183 & 74.063 & 1.91 & 3279 & $\mathrm{C}$ \\
\hline 31 & -82.399 & 74.234 & 0.61 & 2906 & $\mathrm{C}$ \\
\hline 32 & -82.495 & 74.161 & 0.76 & 2776 & $\mathrm{C}$ \\
\hline 33 & -82.263 & 74.334 & 0.36 & 3150 & $\mathrm{C}$ \\
\hline 34 & -82.396 & 74.576 & 2.64 & 2914 & $\mathrm{C}$ \\
\hline 35 & -82.339 & 74.615 & 1.17 & 3038 & $\mathrm{C}$ \\
\hline 36 & -82.997 & 74.484 & 0.32 & 2806 & - \\
\hline 37 & -82.465 & 74.869 & 0.85 & 2793 & $\mathrm{C}$ \\
\hline 38 & -82.450 & 74.879 & 0.67 & 2821 & $\mathrm{C}$ \\
\hline 39 & -81.002 & 75.986 & 0.43 & 3080 & - \\
\hline 40 & -82.288 & 76.994 & 1.45 & 2974 & $\mathrm{D}$ \\
\hline 41 & -81.795 & 77.174 & 0.64 & 3058 & - \\
\hline 42 & -82.347 & 77.644 & 0.51 & 2795 & $\mathrm{D}$ \\
\hline 43 & -82.425 & 77.963 & 2.41 & 2421 & $\mathrm{D}$ \\
\hline 44 & -82.412 & 77.966 & 1.33 & 2457 & $\mathrm{D}$ \\
\hline 45 & -82.398 & 77.969 & 1.78 & 2564 & $\mathrm{D}$ \\
\hline 46 & -82.549 & 78.273 & 3.64 & 2164 & $\mathrm{D}$ \\
\hline 47 & -82.507 & 78.282 & 0.98 & 2267 & D \\
\hline 48 & -82.492 & 78.285 & 0.87 & 2327 & $\mathrm{D}$ \\
\hline 49 & -82.453 & 78.295 & 1.07 & 2359 & $\mathrm{D}$ \\
\hline 50 & -81.258 & 78.526 & 0.37 & 3030 & - \\
\hline 51 & -81.918 & 79.362 & 0.44 & 3038 & $\mathrm{E}$ \\
\hline 52 & -83.703 & 79.595 & 0.45 & 3375 & - \\
\hline 53 & -81.818 & 79.999 & 0.31 & 3244 & $\mathrm{E}$ \\
\hline 54 & -80.330 & 80.000 & 1.07 & 3209 & G \\
\hline 55 & -81.746 & 80.312 & 0.79 & 3332 & $\mathrm{E}$ \\
\hline 56 & -81.784 & 80.314 & 0.68 & 3312 & $\mathrm{E}$ \\
\hline 57 & -82.888 & 80.721 & 1.09 & 3275 & I \\
\hline 58 & -81.740 & 80.935 & 0.79 & 3307 & $\mathrm{E}$ \\
\hline 59 & -80.677 & 80.830 & 0.94 & 3582 & G \\
\hline 60 & -80.280 & 80.796 & 1.82 & 3424 & G \\
\hline 61 & -83.674 & 81.623 & 0.61 & 3340 & - \\
\hline 62 & -82.795 & 81.427 & 0.57 & 3151 & I \\
\hline 63 & -80.628 & 81.100 & 0.31 & 3547 & G \\
\hline 64 & -80.302 & 81.065 & 1.31 & 3423 & G \\
\hline 65 & -82.150 & 81.641 & 0.40 & 2787 & $\mathrm{E}$ \\
\hline 66 & -82.123 & 81.960 & 0.78 & 2861 & $\mathrm{E}$ \\
\hline 67 & -82.114 & 81.957 & 0.86 & 2842 & $\mathrm{E}$ \\
\hline 68 & -81.950 & 81.919 & 0.92 & 3130 & $\mathrm{E}$ \\
\hline 69 & -82.006 & 81.933 & 0.67 & 3021 & $\mathrm{E}$ \\
\hline
\end{tabular}

Table 1. (continued)

\begin{tabular}{|c|c|c|c|c|c|}
\hline Number & Lat & Lon & $\begin{array}{l}\text { Length } \\
(\mathrm{km})\end{array}$ & $\begin{array}{c}\text { Ice Thickness } \\
(\mathrm{m})\end{array}$ & Network \\
\hline 70 & -82.018 & 81.936 & 1.04 & 2990 & E \\
\hline 71 & -81.574 & 81.835 & 0.61 & 3434 & $\mathrm{~F}$ \\
\hline 72 & -81.584 & 81.837 & 0.30 & 3425 & $\mathrm{~F}$ \\
\hline 73 & -82.697 & 82.470 & 1.42 & 2891 & I \\
\hline 74 & -81.541 & 82.136 & 0.54 & 3447 & $\mathrm{~F}$ \\
\hline 75 & -79.877 & 81.786 & 1.25 & 2999 & - \\
\hline 76 & -81.414 & 82.703 & 0.92 & 3546 & $\mathrm{~F}$ \\
\hline 77 & -81.378 & 82.993 & 0.43 & 3536 & $\mathrm{~F}$ \\
\hline 78 & -81.512 & 84.560 & 0.40 & 3356 & $\mathrm{~F}$ \\
\hline 79 & -80.911 & 84.259 & 0.91 & 3577 & - \\
\hline 80 & -81.516 & 84.867 & 0.98 & 3321 & $\mathrm{~F}$ \\
\hline 81 & -83.248 & 69.327 & 1.01 & 2848 & A \\
\hline 82 & -83.277 & 70.746 & 1.63 & 2739 & A \\
\hline 83 & -83.282 & 71.039 & 2.39 & 2767 & A \\
\hline 84 & -82.949 & 69.703 & 1.24 & 3261 & A \\
\hline 85 & -82.985 & 71.468 & 0.52 & 3176 & B \\
\hline 86 & -82.998 & 72.233 & 0.91 & 3161 & B \\
\hline 87 & -83.060 & 80.972 & 2.38 & 3316 & I \\
\hline 88 & -82.396 & 72.716 & 0.84 & 2962 & - \\
\hline 89 & -82.421 & 74.389 & 0.66 & 2932 & $\mathrm{C}$ \\
\hline 90 & -82.425 & 74.718 & 1.27 & 2899 & $\mathrm{C}$ \\
\hline 91 & -82.426 & 74.775 & 0.32 & 2873 & $\mathrm{C}$ \\
\hline 92 & -82.453 & 78.236 & 0.72 & 2343 & D \\
\hline 93 & -82.453 & 78.281 & 0.34 & 2373 & D \\
\hline 94 & -82.453 & 78.164 & 0.50 & 2332 & D \\
\hline 95 & -82.453 & 78.132 & 0.49 & 2329 & D \\
\hline 96 & -82.452 & 78.107 & 0.29 & 2339 & D \\
\hline 97 & -82.452 & 78.074 & 0.65 & 2325 & D \\
\hline 98 & -82.452 & 78.038 & 0.29 & 2310 & D \\
\hline 99 & -82.152 & 81.559 & 0.89 & 2765 & E \\
\hline 100 & -82.151 & 81.633 & 0.31 & 2799 & E \\
\hline 101 & -82.150 & 81.783 & 0.93 & 2779 & E \\
\hline 102 & -81.543 & 82.122 & 0.55 & 3431 & $\mathrm{~F}$ \\
\hline 103 & -81.519 & 84.892 & 1.50 & 3324 & $\mathrm{~F}$ \\
\hline 104 & -80.919 & 84.273 & 1.55 & 3548 & - \\
\hline 105 & -80.639 & 81.022 & 0.79 & 3542 & G \\
\hline
\end{tabular}

${ }^{a}$ Lat and Lon represent the location of the pick center, ice thickness represents the mean value of all points within the pick, and a pick is counted as within a network if one of its endpoints is within $5 \mathrm{~km}$ of any of the network paths. Length denotes along track length.

the flight lines intersect multiple water bodies, in other cases they intersect only a single water body, and in a few cases no water bodies are observed, despite the presence of water bodies in adjacent flight lines crossing the same valley. Examples of this variable arrangement are shown in Figure 10. Where network A is subparallel to a flight line (Figure 10a) we observe one unclear and four clear picks, three of which contain $4 \sigma$ anomalies. Where network A is subperpendicular to a flight line (Figure 10c) we only observe a single clear pick containing $4 \sigma$ anomalies. Yet despite the variability in valley scale arrangement, all of the water bodies in this figure are within error margin of the same hydraulic head (Figure 10, row 2), suggesting that they are hydraulically connected to one another.

[21] As a whole, the networks are either hydraulically flat or sloping downward in the direction predicted by applying a routing algorithm to the gridded hydraulic head (Figure 11, cf. Figure 9). We determine the gradient of hydraulic head (Figure 11, Table 2) and ice thickness (Table 2 only) for each network by taking a best fit line to the values for the individual water bodies within that network. Networks B, C, $\mathrm{D}$, and $\mathrm{H}$ are flat and do not have statistically significant hydraulic gradients. We assign drainage direction for those networks based on the presence of freeze-on ice near one 

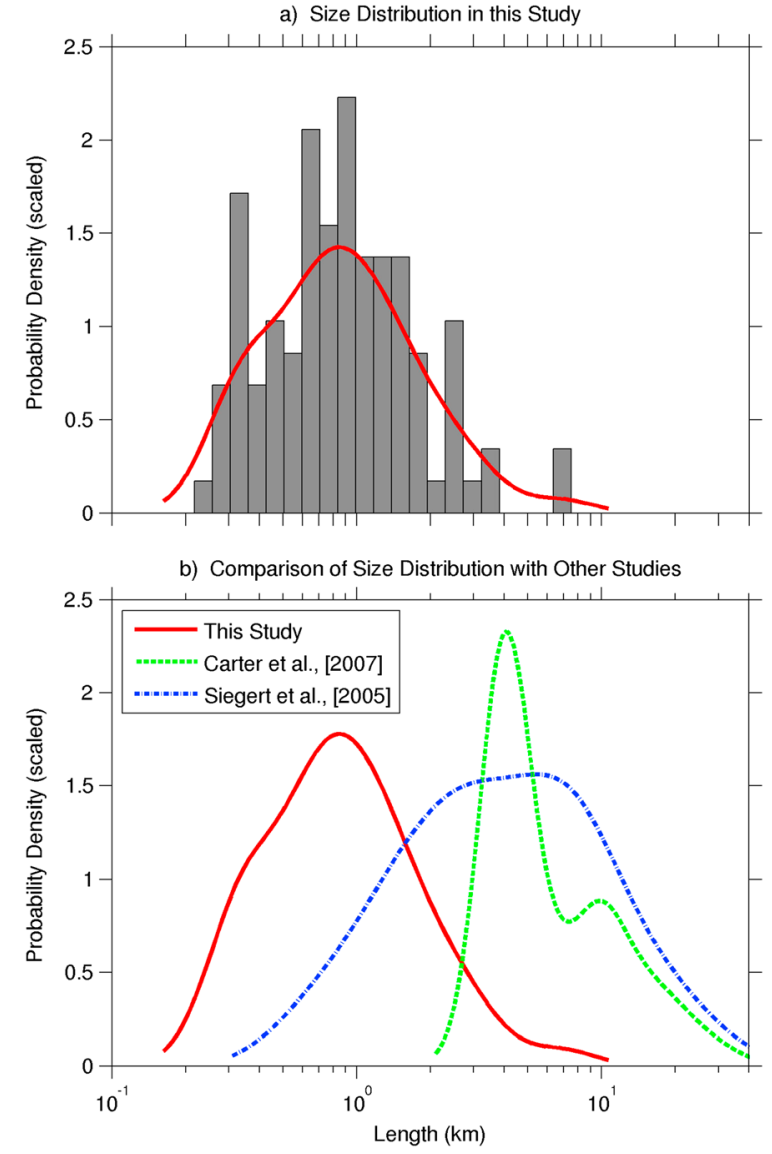

Figure 8. Size distribution of water bodies: (a) distribution of the logarithm of water body length for the intersection set (clear picks containing $4 \sigma$ reflectivity anomalies). Gray bars represent the histogram and the red line represents a kernel density estimate of the underlying probability density function using a Gaussian kernel and (b) comparison of the probability density function in (a) with similar functions derived from published subglacial lake inventories.

endpoint and the direction determined by the routing algorithm. It is possible that on short timescales water can flow either uphill or downhill within these networks in response to minor changes in the ice surface or effective pressure [Wright et al., 2008]. However, the large-scale structure of the hydraulic head is determined by the overall ice surface geometry of Dome A (Figures 1a and 1c). Over long timescales $(<\sim 100 \mathrm{ka})$ the water must flow uphill and feed the freeze-on ice identified by Bell et al. [2011a], assuming that Dome A has remained stable.

\section{Discussion}

\subsection{Attenuation Rate}

[22] We image subglacial hydrologic networks in the Gamburtsevs using RES. Because our results partially depend on using a linear best fit to bed returned power as a function of ice thickness $\left(\left[\mathrm{P}^{\mathrm{c}}\right]_{\mathrm{dB}}\right.$ vs $\left.\mathrm{D}\right)$ to estimate an attenuation correction, it is important to examine the weaknesses of this method. A single regional attenuation correction can be inaccurate if basal reflectivity depends systematically on ice thickness. Matsuoka [2011] has demonstrated that when bed reflectivity depends on ice thickness a linear best fit can underestimate the attenuation correction. If basal reflectivity has a systematic dependence on ice thickness that dependence will contaminate the best fit slope, and the regional attenuation correction will remove part of the targeted reflectivity signal in addition to the attenuation signal. Basal reflectivity can depend systematically on ice thickness if there is a specific depth below which water is found and above which the bed is frozen.

[23] A single regional attenuation correction is, however, appropriate for the Gamburtsevs because ponded water occupies an extremely small fraction $(<1 \%)$ of the total basal area. Thus, the area-averaged basal reflectivity is primarily that of a rock-ice interface and is effectively independent of ice thickness. To test this, we have tried recomputing the best fit without all potential water bodies $(3 \sigma, 4 \sigma$, unclear picks, clear picks). The best fit one way attenuation rate only changes by $0.31 \mathrm{~dB} / \mathrm{km}$, corresponding to maximum reflectivity anomaly errors of $0.9 \mathrm{~dB}$, substantially less than the crossover errors of $6.0 \mathrm{~dB}$.

[24] Our interpreted networks are also robust against larger changes in attenuation rate. MacGregor et al. [2012] modeled englacial thermal structure and attenuation rate along the Vostok flowline, a glaciologically similar setting to Dome A. The depth-averaged attenuation rates in their model ranged between 5.8 and $11.8 \mathrm{~dB} / \mathrm{km}$, with the latter value being close to our best fit regional attenuation correction. We calculate reflectivity anomalies using attenuation rates of $5.8 \mathrm{~dB} / \mathrm{km}$ (near MacGregor et al. 's lowest value) and $17.4 \mathrm{~dB} / \mathrm{km}$ (triple MacGregor et al. 's lowest value and $\sim 50 \%$ larger than our value). All of our interpreted networks retain $3 \sigma(+19.4 \mathrm{~dB})$ reflectivity anomalies under both extremely high and extremely low attenuation rates, and six of the nine (all the networks except B, F, and $\mathrm{H}$ ) retain $4 \sigma$ $(+25.9 \mathrm{~dB})$ reflectivity anomalies as well.

\subsection{Valley-Scale Configuration}

[25] The networks are formed from many kilometer-scale water bodies with a variable small-scale morphology. The vast majority of individual water bodies have along-track widths less than the mean ice thickness of $2.5 \mathrm{~km}$. As a whole, the population of Gamburtsev water bodies is smaller than previously published populations, reflecting both a tight grid spacing that allows us to observe small water bodies and rugged basal topography that prevents the formation of large water bodies. The water networks occur within subsections of the dendritic valley networks that dominate the Gamburtsevs, and are between 20 and $103 \mathrm{~km}$ long.

[26] The water networks in the Gamburtsevs reoccupy a system of alpine overdeepenings formed by valley glaciers in the early growth phase of the EAIS. The overdeepenings form a series of bedrock depressions along valley floors where water generated by subglacial melt collects. This "string of beads" morphology [Benn and Evans, 1998] explains why flight lines that happened to be parallel to the water networks detected a large number of water bodies, whereas flight lines that were oblique to the networks detected few or none at all. We do not observe all the connections between these water bodies, but simple flow-routing algorithms and hydraulic head values between adjacent water bodies (Figures 9-11) suggest they exist. In addition, we observe relatively little water in the upper reaches of the main 


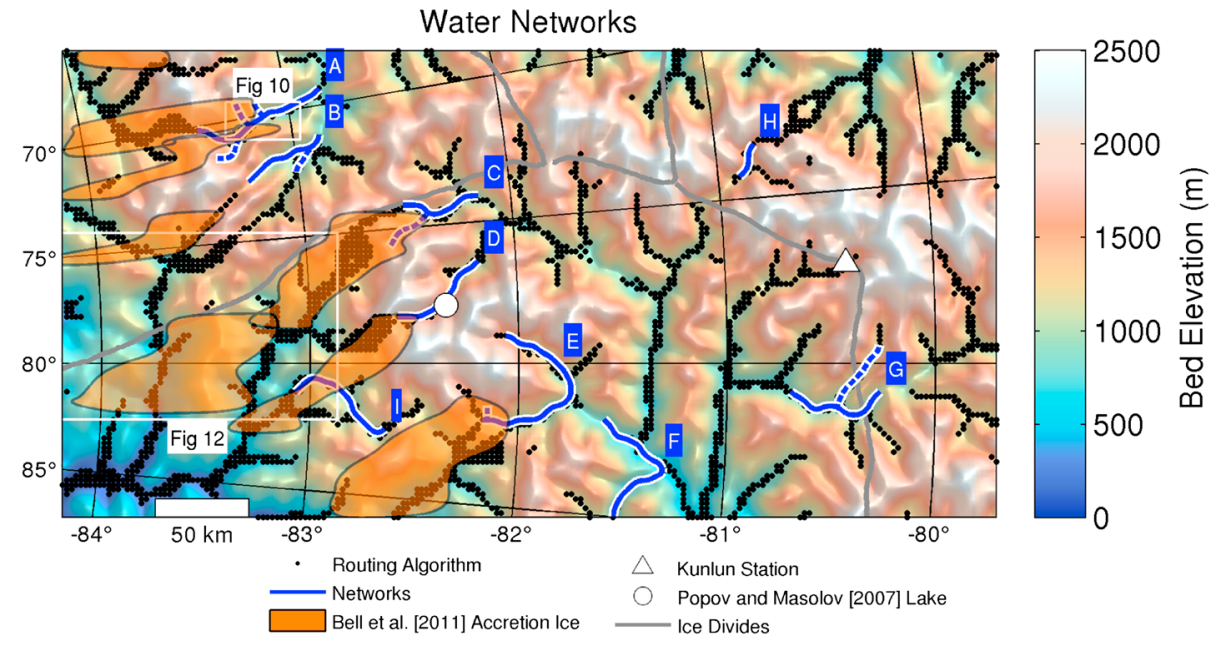

Figure 9. Routing algorithm and interpreted networks (A-I) overlain on bed elevation with hillshading identical to Figure $4 \mathrm{~b}$. Black dots from the routing algorithm represent all grid cells with catchment area greater than $250 \mathrm{~km}^{2}$. Solid blue lines represent the main path of each network and dashed blue lines represent tributaries or distributaries. The orange patches represent the "valley head" accretion plumes identified by Bell et al. [2011a]. Note that the accreted ice bodies form at their upstream ends (upper right in this figure) and are subsequently advected downstream by the ice flow. Some of the water networks terminate at the start of the accretion plumes. The lake identified by Popov and Masolov [2007] in Russian RES data taken in the late 1980s is lake \#94 in the compilation by Siegert et al. [2005].

trunk valleys and in the southeast corner of the grid (Figures 4, 6, and 9) despite thick ice in these regions. The lack of water in these regions may be because downhill flow encourages rapid evacuation and discourages ponding, or because the bed is cold here and meltwater is not present. A cold bed could be caused by changes in geothermal flux or accumulation rate.

[27] The Gamburtsev water networks transport mass and energy along the bedrock valleys. Where water is generated by basal melt, both mass and latent heat are transferred from the ice sheet to the basal hydrologic system. The mass and heat are transported by the hydrologic networks to freezeon locations and returned to the ice sheet, although some water may pass through the freeze-on locations. We do not observe water bodies downstream of the freeze-on locations, but because our methods are conservative we cannot preclude the possibility that water passes through the freeze-on locations. The Gamburtsev water networks form an alternate pathway for rapidly transporting mass and energy between widely spaced parts of the ice sheet.

\subsection{Drainage Pathways}

[28] Drainage pathways in the Gamburtsevs are controlled by bed topography, but drainage direction is controlled by the ice sheet surface. The water networks in the Gamburtsevs fall largely on the bed-dominated side of the beddominated to surface-dominated continuum of subglacial water networks because they are confined to pre-existing bedrock depressions. However, the valley walls that confine the water to the pre-existing networks are steeper than the valley floors that determine drainage direction within those networks. Valley floor slopes are low enough that drainage direction within the bed-confined networks is determined by the ice sheet surface. The modern subglacial water system

Table 2. List of Water Networks

\begin{tabular}{|c|c|c|c|c|c|c|c|c|}
\hline Network & $\begin{array}{l}\text { Length } \\
(\mathrm{km})\end{array}$ & $\begin{array}{c}\text { Hydraulic } \\
\text { Gradient }(\mathrm{m} / \mathrm{km})\end{array}$ & $\begin{array}{l}\text { Hydraulic Gradient } \\
\text { Uncertainty }(\mathrm{m} / \mathrm{km})\end{array}$ & $\begin{array}{c}\text { Ice Thickness } \\
\text { Gradient }(\mathrm{m} / \mathrm{km})\end{array}$ & $\begin{array}{l}\text { Ice Thickness Gradient } \\
\text { Uncertainty }(\mathrm{m} / \mathrm{km})\end{array}$ & $\begin{array}{l}\text { Catchment } \\
\text { Area }\left(\mathrm{km}^{2}\right)\end{array}$ & $\begin{array}{l}\text { No. Water } \\
\text { Bodies }\end{array}$ & $\begin{array}{l}\text { Termination } \\
\text { Style }\end{array}$ \\
\hline A & 75 & -0.27 & 0.13 & -13.0 & 1.2 & 4686 & 24 & freeze-on \\
\hline B & 47 & -0.28 & 0.34 & -10.2 & 2.6 & 2501 & 9 & $\begin{array}{l}\text { short of } \\
\text { freeze-on }\end{array}$ \\
\hline $\mathrm{C}$ & 44 & -0.06 & 0.22 & -13.8 & 2.1 & 3168 & 15 & freeze-on \\
\hline D & 56 & -0.21 & 0.25 & -22.6 & 2.5 & 8656 & 16 & freeze-on \\
\hline E & 103 & -0.92 & 0.12 & -5.3 & 2.1 & 3969 & 19 & freeze-on \\
\hline $\mathrm{F}$ & 87 & -0.53 & 0.12 & -1.1 & 1.8 & 8367 & 9 & $\begin{array}{l}\text { exit survey } \\
\text { area }\end{array}$ \\
\hline G & 58 & -0.40 & 0.15 & 3.0 & 1.4 & 4097 & 6 & unknown \\
\hline $\mathrm{H}$ & 20 & -0.24 & 0.81 & -12.9 & 6.9 & 1762 & 2 & freeze-on \\
\hline I & 64 & -1.50 & 0.22 & 7.9 & 3.4 & 2322 & 4 & unknown \\
\hline
\end{tabular}

${ }^{\mathrm{a}}$ Length represents the length of the main path only, and both hydraulic head gradient and ice thickness gradient represent best-fit slopes to the values at individual water bodies along the main path. Note that some networks contain side-paths in addition to the main path. Catchment area represents the maximum upstream area as computed by the multiple slope algorithm for any grid cell within any of the paths. The number of water bodies represents the members of Table 1 within $5 \mathrm{~km}$ of any of the network paths. 
WOLOVICK ET AL.: SUBGLACIAL WATER NETWORKS UNDER DOME A

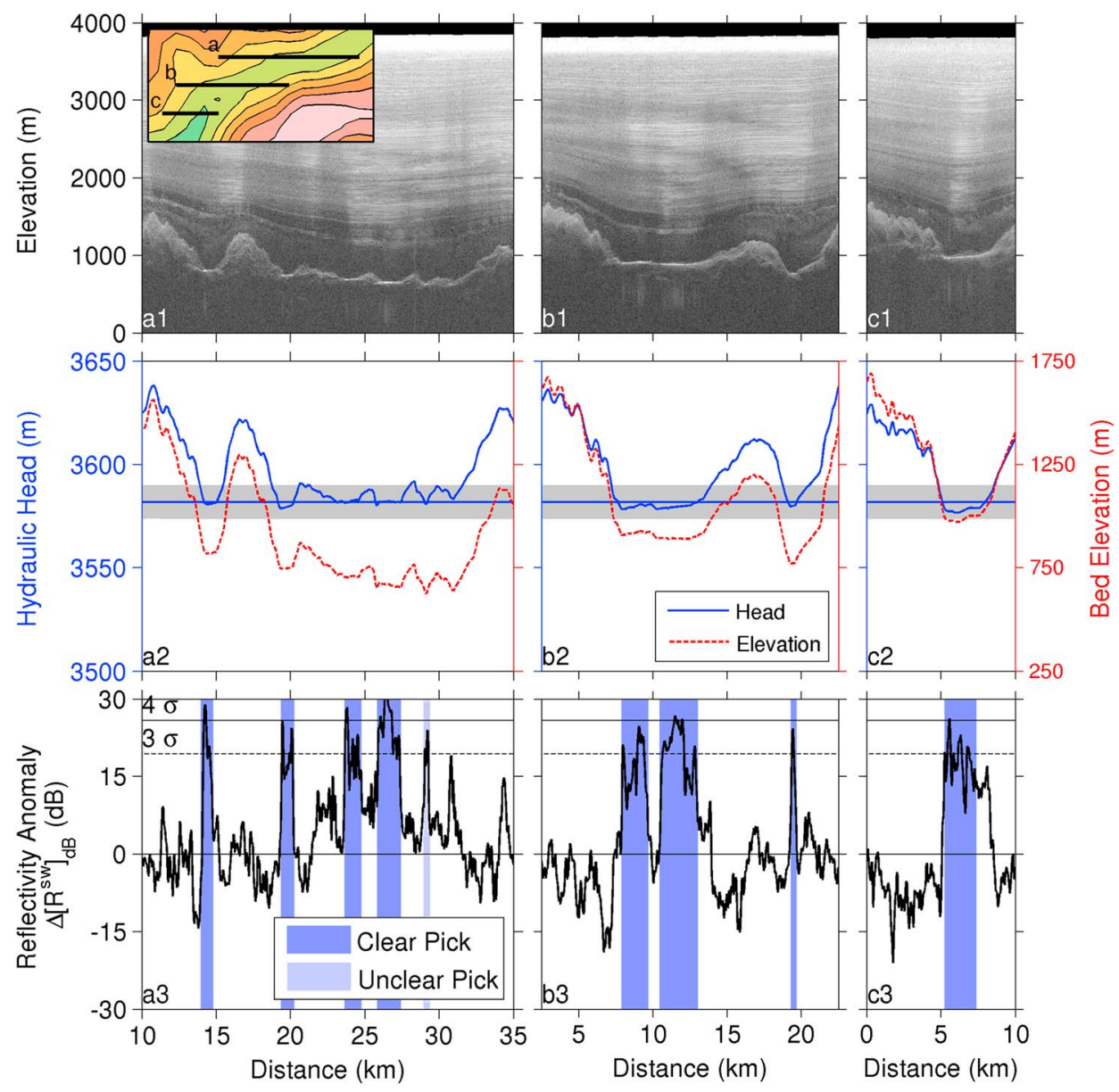

Figure 10. Network A: detail of 3 sequential flight lines. The first row (a1, b1, c1) shows the echograms in the same color scale as Figure 3. The second row (a2, b2, c2) shows bed elevation and hydraulic head. Note scale change of elevation in second row relative to first row, and of head relative to elevation. The horizontal line shows the hydraulic head in the first picked water body in a 2 extrapolated to the rest of the network, and the shading represents the uncertainty in hydraulic head. The third row (a3, b3, c3) shows short-wavelength reflectivity anomalies. The dark (light) blue regions show clear (unclear) manual picks, and the solid (dashed) horizontal lines show the 4 (3) $\sigma$ cutoff. 40 x $20 \mathrm{~km}$ inset map shows hydraulic head with $10 \mathrm{~m}$ contours. Location of inset map given in Figure 9.

occupies the same set of morphological features as the preEAIS alpine glacial lake system, but it is free to move water either uphill or downhill through that system.

[29] We term drainage within the Gamburtsevs "bed routed, surface directed," meaning that the flow is confined to pre-existing bedrock valleys but can move either uphill or downhill within those valleys depending on the ice surface slope. This style of subglacial drainage will occur wherever the ice sheet bed contains troughs unrelated to ice flow. The basal topography must be organized into valleys with wall slopes steeper than 11 times the ice surface and floor slopes shallower than 11 times the ice surface. This situation could arise in other areas of East Antarctica with rugged basal topography such as the Recovery Highlands, Ridge B or Dome C, but it could also arise in an area of relatively flat basal topography with valleys, such as interior Greenland (e.g., upstream of Petermann Glacier [Bell et al., 2011b]), or the beds of the former Laurentide and Fennoscandian ice sheets [Benn and Evans, 1998]. This situation will not arise in places like the West Antarctic ice streams where bed troughs are shallow enough that changes in the ice surface can cause water to jump between adjacent troughs, resulting in lateral piracy by adjacent ice streams [Alley et al., 1994].

\subsection{Possible Temporal Variability}

[30] There is indirect evidence for long-term (10s of ka) variability in the Gamburtsev water networks from the along-flow structure of the accretion plumes. The apparent separation $(\sim 20 \mathrm{~km})$ between the end of network B and a nearby accretion plume implies accretion has been inactive there for $20 \mathrm{ka}$, assuming a characteristic ice velocity of $1 \mathrm{ma}^{-1}$, although other factors may explain the apparent separation (section 3.4). In addition, the plume produced by network $\mathrm{C}$ displays substantial along-flow variability. Morphologically distinct reflectors within this plume can be traced coherently for $\sim 30 \mathrm{~km}$ over multiple flight lines before abruptly disappearing (Figure 12), implying a persistence timescale of $\sim 30 \mathrm{ka}$. Long-term variability in the networks could be produced by surface climate changes propagating to the bed and causing changes in basal thermal state, or by internal dynamics of the ice sheet and hydrologic system. 

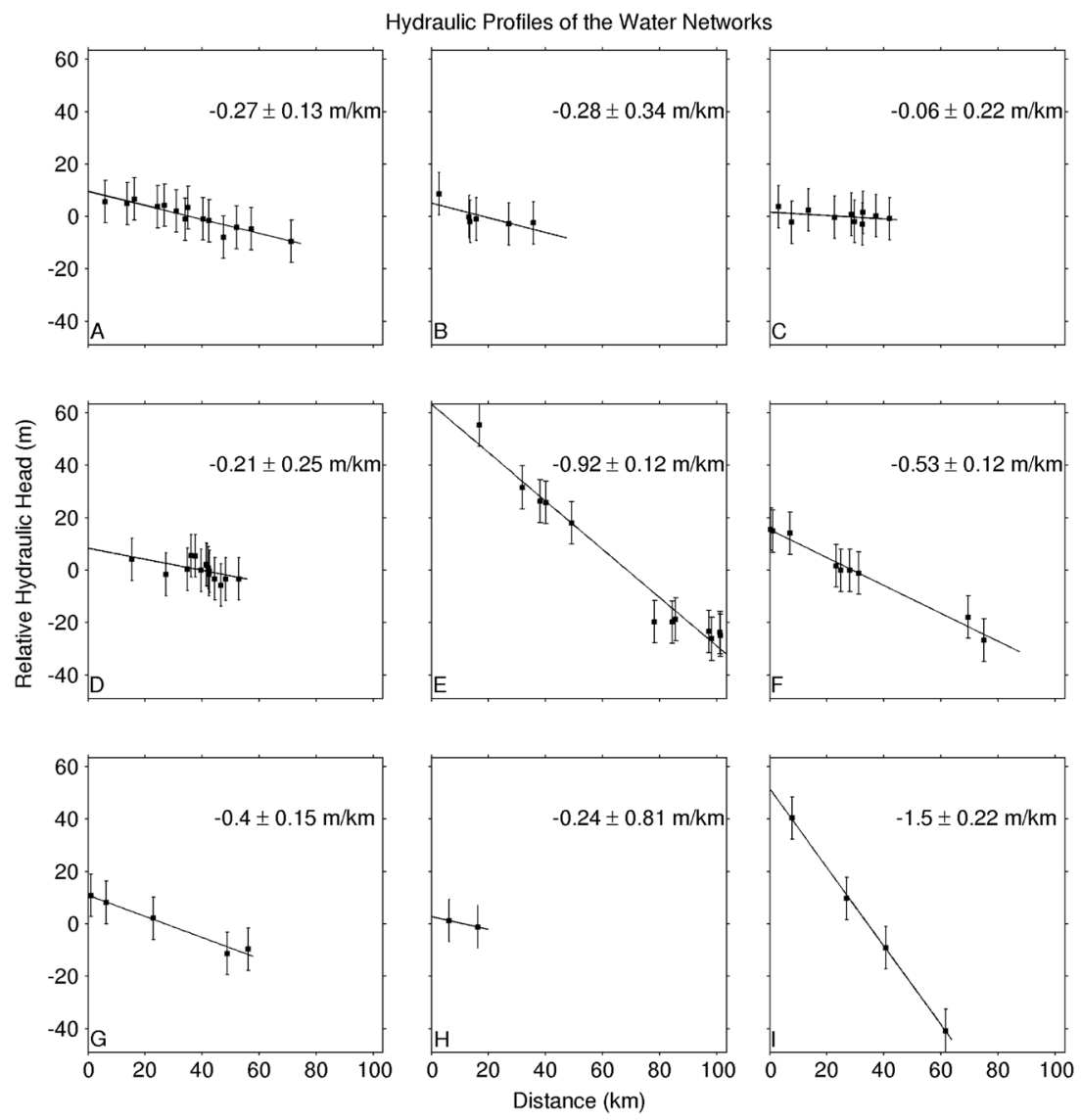

Figure 11. Hydraulic head of water bodies along the main paths (solid blue lines in Figure 9) of each network. Hydraulic head is plotted relative to the mean value within each network so that all networks can be plotted on the same scale. Only water bodies within the intersection set (clear picks containing $4 \sigma$ reflectivity anomalies) are shown.

[31] Short-term variability in the water networks may be caused by changes in drainage morphology. Water networks elsewhere in Antarctica with similar hydraulic gradients to the Gamburtsev networks drain episodically. Wingham et al. [2006] discovered active drainage connecting subglacial lakes separated by over $290 \mathrm{~km}$ near Dome C in East Antarctica along a hydraulic head gradient of $5.1 \times 10^{-4}$, in the midrange of the gradients along the Gamburtsev networks (Table 2), and attributed that drainage to sudden discharge through subglacial tunnels. Fricker et al. [2007] found episodic drainage between active subglacial lakes underneath Whillans Ice Stream along a hydraulic head gradient of 3-6 $\times 10^{-4}$, also in the midrange of the gradients along the Gamburtsev networks. Fricker et al. [2010] found episodic drainage between subglacial lakes underneath MacAyeal Ice Stream along a hydraulic head gradient of $1.7 \times 10^{-3}$, on the high end of the gradients along the Gamburtsev networks. On the other hand, Smith et al. [2009] made a comprehensive inventory of actively filling and draining lakes throughout Antarctica using repeat-track satellite laser altimetry and did not discover any near Dome A. However, the smallest lakes they could detect were $\sim 5 \mathrm{~km}$ long [Smith et al., 2009, Figure 5], and all but two of the Gamburtsev water bodies are smaller than this. Based on the similar hydraulic gradients of episodically connected networks elsewhere in Antarctica to the Gamburtsev networks, we speculate that the individual water bodies within the Gamburtsev networks are also connected by episodic discharge. A rigorous investigation of the time dependence of the connections within the Gamburtsev water networks will require repeat radar surveys in the future.

\section{Conclusion}

[32] We have identified subglacial water networks with lengths from 20 to $103 \mathrm{~km}$ within the Gamburtsev Subglacial Mountains using two methods to analyze radio-echo sounding data. Using both manual digitization and quantitative reflectivity anomaly analysis we have been able to track the change of the network configuration with distance downflow. These networks are characterized by a complex configuration containing a multitude of kilometer-scale water bodies in a manner similar to subaerial alpine lakes. The individual water bodies are smaller on average than water bodies that have been discovered by previous surveys [Siegert et al., 2005; Carter et al., 2007], reflecting both a tighter line spacing and rugged basal topography that prevents the formation of large water bodies. Based on this result we emphasize the importance of high-resolution surveys for understanding subglacial hydrology. We cannot constrain the timing of the water flow between the individual water bodies in each network, but similarities in hydraulic gradient to other Antarctic water systems suggest drainage may be episodic. In addition, analysis of variability in the accretion plumes produced by some of the networks suggests their extent may reflect 


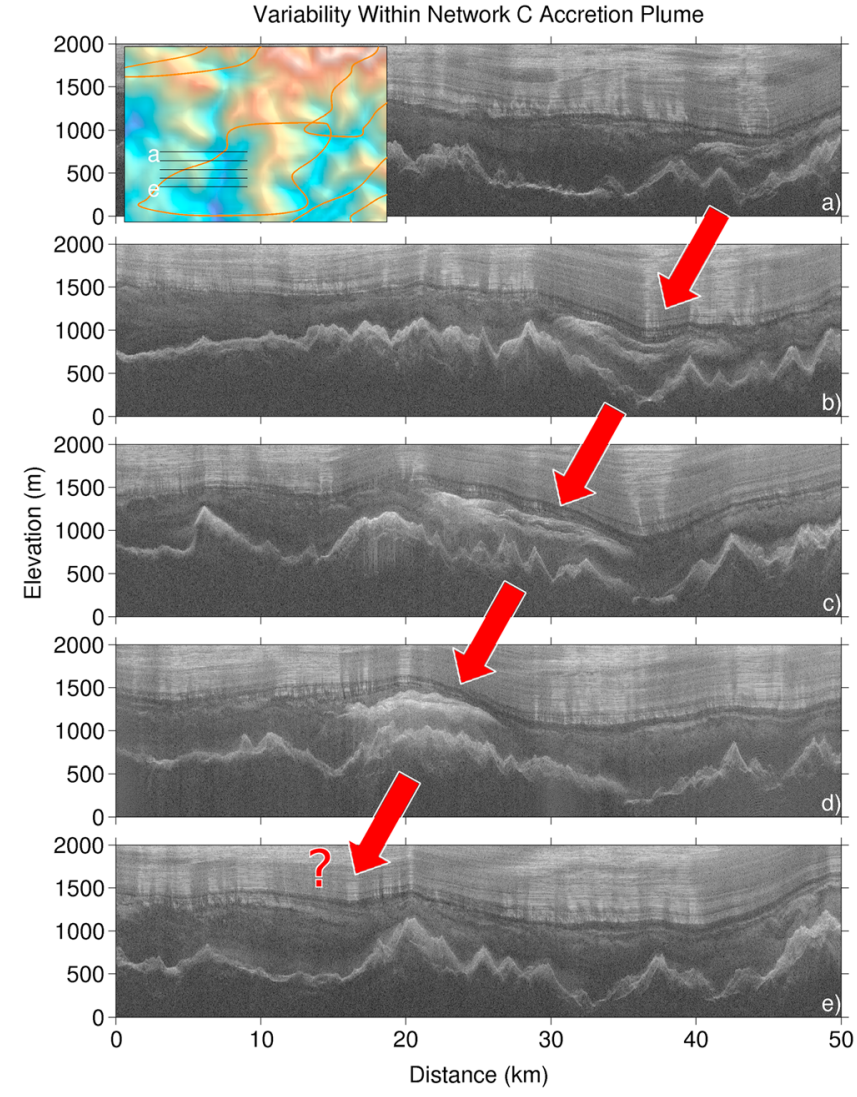

Figure 12. Sequential echograms crossing the accretion plume produced by network C. Color scale is the same as Figure 3. Red arrows indicate the advection by ice flow of a morphologically distinct accretion unit in first panel through the rest of the figure. This unit can be recognized by having distinct upper and lower surfaces with a radar-transparent layer in the middle. Upstream of this figure the accretion plume has a different morphology, but can still be traced coherently (not shown). Question mark in fifth panel indicates that the accretion unit terminated abruptly somewhere between fourth and fifth panels. Because this is the downflow end of the accretion plume, the termination could represent the time when the accretion process activated in the past. Spacing between flight lines is $5 \mathrm{~km}$. Inset map represents bed elevation with identical color scale and hill shading as Figure 4b. Orange lines represent outline of Bell et al. [2011] accretion units represented in Figure 9. Location of inset map given in Figure 9.

changes in the basal thermal state caused by either changes in the internal dynamics of the ice sheet and hydrologic system or changes in surface temperature and accumulation.

[33] The water bodies form in depressions created by alpine glaciers during the early growth phase of the East Antarctic Ice Sheet. These depressions are able to trap subglacial water at present because of the high bedrock relief in the Gamburtsevs compared to surface relief. However, bedrock slopes along valley floors are lower than bedrock slopes down valley walls, allowing the ice surface to dictate the direction, but not the route, of subglacial water drainage. Subglacial water within the Gamburtsevs can flow either uphill or downhill along valley floors depending on the gradient of the ice surface. When the networks flow uphill, they feed organized plumes of accretion ice, indicating source to sink transport within the basal hydrologic system. The mountain valleys of the Gamburtsevs are pathways for the transport of mass and energy between widely separated parts of the ice sheet.

[34] We propose that subglacial water exists across a continuum of scales, from tens of kilometer giants like Lake Vostok through submeter scale linked cavities. There is no sharp physical threshold separating classic "subglacial lakes" from other forms of subglacial water, only a limit in detectability. In the Gamburtsev water networks, long distance (up to $103 \mathrm{~km}$ ) transport of mass and energy is accomplished through strings of small $(\sim 850 \mathrm{~m})$ discontinuous individual water bodies. These individual water bodies represent a step by observational glaciology toward bridging the gap between small channels or cavities and large subglacial lakes.

[35] Acknowledgments. We thank all field participants in the AGAP project for their hard work under difficult conditions. Kirsty Langley, Roger Buck, and Daniel Fischel provided insightful comments on earlier versions of the manuscript. This work was funded through NSF OPP awards ANT0632292, ANT-0537752, and ANT-0636584.

\section{References}

Alley, R. B., S. Anandakrishnan, C. R. Bentley, and N. Lord (1994), A waterpiracy hypothesis for the stagnation of Ice Stream C, Antarctica, Ann. Glaciol., 20(1), 187-194.

Bamber, J. L., J. L. Gomez-Dans, and J. A. Griggs (2009), A new 1 km digital elevation model othe Antarctic derived from combined satellite radar and laser data - part 1: data and methods, Cryosphere, 3(1), 101-111. doi:10.5194/tc-3-101-2009.

Bell, R. E., F. Ferraccioli, T. T. Creyts, D. Braaten, H. Corr, I. Das, D. Damaske, N. Frearson, T. A. Jordan, K. Rose, M. Studinger, and M. J. Wolovick (2011a), Widespread persistent thickening of the East Antarctic Ice Sheet by freezing from the base, Science, 331(6024), 1592-1595, doi: $10.1126 /$ science. 1200109.

Bell, R. E., K. J. Tinto, M. J. Wolovick, A. E. Block, N. Frearson, I. Das, A. Abdi, T. T. Creyts, J. R. Cochran, B. M. Csatho, and G. S. Babonis (2011b), Ice bridge provides novel evidence for thick units of basal freeze-on ice along Petermann Glacier, Greenland, AGU, Fall Meet., Abstract C41E-0469.

Benn, D. I., and D. J. A. Evans (1998), Glaciers \& Glaciation, 816 pp., Arnold, London.

Blankenship, D. D., S. P. Carter, J. W. Holt, D. L. Morse, M. E. Peters, and D. A. Young (2009), Antarctic Subglacial Lake Classification Inventory, Boulder, Colorado USA, National Snow and Ice Data Center.

Bo, S., M. J. Siegert, S. M. Mudd, D. Sugden, S. Fujita, C. Xiangbin, J. Yunyun, T. Xueyuan, and L. Yuansheng (2009), The Gamburtsev Mountains and the origin and early evolution of the Antarctic Ice Sheet, Nature, 459(7247), 690-693, doi:10.1038/nature08024.

Bowman, A.W., and A. Azzalini (1997), Applied Smoothing Techniques for Data Analysis, 208 pp., Oxford University Press, New York.

Carter, S. P., D. D. Blankenship, M. E. Peters, D. A. Young, J. W. Holt, and D. L. Morse (2007), Radar-based subglacial lake classification in Antarctica, Geochem. Geophys. Geosyst., 8, doi:10.1029/2006GC001408.

Clarke, G. K. C (2005), Subglacial processes, Annu. Rev. Earth Planet. Sci., 33, 247-276, doi:10.1146/annurev.earth.33.092203.122621.

Cox, S. E., S. N. Thomson, P. W. Reiners, S. R. Hemming, and T. van de Flierdt (2010), Extremely low long-term erosion rates around the Gamburtsev Mountains in interior East Antarctica, Geophys. Res. Lett., 37, doi:10.1029/2010GL045106.

Cuffey, K. M., and W. S. B. Paterson (2010), The Physics of Glaciers, 4th ed., 704 pp., Butterworth-Heineman/Elsevier, Burlington, Mass.

Dowdeswell, J. A., and M. J. Siegert (1999), The Dimensions and Topographic Setting of Antarctic Subglacial Lakes and Implications for Large-scale Water Storage Beneath Continental Ice Sheets. Geol. Soc. Am. Bull., 111(2): 254-263.doi:10.1130/0016-7606(1999)111<0254:TDATSO > 2.3.CO;2.

Dowdeswell, J. A., and M. J. Siegert (2003), The physiography of modern Antarctic subglacial lakes, Global Planet. Change, 35(3-4), 221-236, doi:10.1016/S0921-8181(02)00128-5.

Ferraccioli, F., C. A. Finn, T. A. Jordan, R. E. Bell, L. M. Anderson, and D. Damaske (2011), East Antarctic rifting triggers uplift of the Gamburtsev Mountains, Nature, 479(7373), 388-U139, doi:10.1038/nature10566. 


\section{WOLOVICK ET AL.: SUBGLACIAL WATER NETWORKS UNDER DOME A}

Flowers, G. E., and G. K. C. Clarke, (1999), Surface and bed topography of Trapridge Glacier, Yukon Territory, Canada: digital elevation models and derived hydraulic geometry, J. Glaciol., 45(149), 165-174.

Fricker, H. A., T. Scambos, R. Bindschadler, and L. Padman (2007), An active subglacial water system in West Antarctica mapped from space, Science, 315(5818), 1544-1548, doi:10.1126/science.1136897.

Fricker, H. A., T. Scambos, S. P. Carter, C. Davis, T. Haran, and I. Joughin (2010), Synthesizing multiple remote-sensing techniques for subglacial hydrologic mapping: application to a lake system beneath MacAyeal Ice Stream, West Antarctica, J. Glaciol., 56(196), 187-199.

Gogineni, S., D. Tammana, D. Braaten, C. Leuschen, T. Akins, J. Legarsky, P. Kanagaratnam, J. Stiles, C. Allen, and K. Jezek (2001), Coherent radar ice thickness measurements over the Greenland Ice Sheet, J. Geophys. Res. Atmos., 106(D24), 33761-33772. doi:10.1029/2001JD900183.

Gray, L., I. Joughin, S. Tulaczyk, V. B. Spikes, R. Bindschadler, and K. Jezek (2005), Evidence for subglacial water transport in the West Antarctic Ice Sheet through three-dimensional satellite radar interferometry, Geophys. Res. Lett., 32(3), doi:10.1029/2004GL021387.

Heliere, F., C. Lin, H. Corr, and D. Vaughan (2007), Radio echo sounding of Pine Island Glacier, West Antarctica: aperture synthesis processing and analysis of feasibility from space, IEEE Trans. Geosci. Remote Sens., 45(8), 2573-2582, doi:10.1109/TGRS.2007.897433.

Jacobel, R. W., K. E. Lapo, J. R. Stamp, B. W. Youngblood, B. C. Welch, and J. L. Bamber (2010), A comparison of basal reflectivity and ice velocity in East Antarctica, Cryosphere, 4(4), 447-452, doi:10.5194/tc-4-447-2010.

Jamieson, S. S. R., D. E. Sugden, and N. R. J. Hulton (2010), The evolution of the subglacial landscape of Antarctica, Earth Planet. Sci. Lett., 293(1-2): 1-27, doi:10.1016/j.epsl.2010.02.012.

Jezek, K., E. Rodriguez, S. P. Gogineni, A. Freeman, J. Curlander, X. Q. Wu, J. Paden, and C. Allen (2006), Glaciers and ice sheets mapping orbiter concept, J. Geophys. Res., 111(E6), doi:10.1029/2005JE002572.

Le Brocq, A. M., A. J. Payne, M. J. Siegert, and R. B. Alley, (2009), A subglacial water-flow model for West Antarctica, J. Glaciol., 55(193), 879-888, doi:10.3189/002214309790152564.

MacGregor, J. A., K. Matsuoka, E. D. Waddington, D. P. Winebrenner, and F. Pattyn (2012), Spatial variation of englacial radar attenuation: modeling approach and application to the Vostok Flowline, J. Geophys. Res., 117(F3), doi:10.1029/2011JF002327.

MacGregor, J. A., D. P. Winebrenner, H. Conway, K. Matsuoka, P. A. Mayewski, and G. D. Clow (2007), Modeling englacial radar attenuation at Siple Dome, West Antarctica, using ice chemistry and temperature data, J. Geophys. Res., 112(F3), doi:10.1029/2006JF000717.
Matsuoka, K. (2011), Pitfalls in radar diagnosis of ice-sheet bed conditions: lessons from englacial attenuation models, Geophys. Res. Lett., 38(5), doi:10.1029/2010GL046205.

Matsuoka, K., D. Morse, and C. F. Raymond (2010), Estimating englacial radar attenuation using depth profiles of the returned power, Central West Antarctica, J. Geophys. Res., 115, doi:10.1029/2009JF001496.

Oswald, G. K. A., and S. P. Gogineni (2008), Recovery of subglacial water extent from Greenland radar survey data, J. Glaciol., 54(184), 94-106, doi:10.3189/002214308784409107.

Oswald, G. K. A., and G. D. Q. Robin (1973), Lakes beneath Antarctic ice sheet, Nature, 245(5423), 251-254, doi:10.1038/245251a0.

Pattyn, F. (2010), Antarctic subglacial conditions inferred from a hybrid ice sheet/ice stream model, Earth Planet. Sci. Lett., 295(3-4), 451-461, doi:10.1016/j.eps1.2010.04.025.

Peters, M. E., D. D. Blankenship, and D. L. Morse (2005), Analysis techniques for coherent airborne radar sounding: application to West Antarctic ice streams, J. Geophys. Res., 110(B6), doi:10.1029/2004JB003222.

Popov, S. V., and V. N. Masolov (2007), Forty-seven new subglacial lakes in the 0-110 degrees E sector of East Antarctica, J. Glaciol., 53(181), 289-297, doi:10.3189/172756507782202856.

Quinn, P., K. Beven, P. Chevallier, and O. Planchon (1991), The prediction of hillslope flow paths for distributed hydrological modeling using digital terrain models, Hydrol. Process., 5(1), 59-79, doi:10.1002/hyp.3360050106.

Remy, F., and B. Legresy (2004), Subglacial hydrological networks in Antarctica and their impact on ice flow, Ann. Glaciol., 39, 67-72, doi:10.3189/ 172756404781814401.

Rignot, E., J. Mouginot, and B. Scheuchl (2011), Ice flow of the Antarctic ice sheet, Science, 333(6048), 1427-1430, doi:10.1126/science.1208336. Shreve, R. L. (1972), Movement of water in glaciers, J. Glaciol., 11(62), 205-214.

Siegert, M. J., S. P. Carter, I. Tabacco, S. Popov, and D. D. Blankenship (2005), A revised inventory of Antarctic subglacial lakes, Antarct. Sci., 17(3), 453-460, doi:10.1017/S0954102005002889.

Siegert, M. J., J. A. Dowdeswell, M. R. Gorman, and N. F. McIntyre (1996), An inventory of Antarctic sub-glacial lakes, Antarct. Sci., 8(3), 281-286. Smith, B., H. A. Fricker, I. R. Joughin, and S. Tulaczyk (2009), An inventory of active subglacial lakes in Antarctica detected by ICESat (2003-2008), J. Glaciol., 55(192), 573-595.

Wingham, D. J., M. J. Siegert, A. Shepherd, and A. S. Muir (2006), Rapid discharge connects Antarctic subglacial lakes, Nature, 440(7087), 1033-1036, doi:10.1038/nature04660. 